ORNL/TM-2011/456

\title{
Quantifying Temperature Effects on Fall Chinook Salmon
}

\section{Prepared by}

\author{
H.I. Jager
}




\title{
DOCUMENT AVAILABILITY
}

Reports produced after January 1, 1996, are generally available free via the U.S. Department of Energy (DOE) Information Bridge.

Web site http://www.osti.gov/bridge

Reports produced before January 1, 1996, may be purchased by members of the public from the following source.

\author{
National Technical Information Service \\ 5285 Port Royal Road \\ Springfield, VA 22161 \\ Telephone 703-605-6000 (1-800-553-6847) \\ TDD 703-487-4639 \\ Fax 703-605-6900 \\ E-mail info@ntis.gov \\ Web site http://www.ntis.gov/support/ordernowabout.htm
}

Reports are available to DOE employees, DOE contractors, Energy Technology Data Exchange (ETDE) representatives, and International Nuclear Information System (INIS) representatives from the following source.

Office of Scientific and Technical Information

\section{P.O. Box 62}

Oak Ridge, TN 37831

Telephone 865-576-8401

Fax 865-576-5728

E-mail reports@osti.gov

Web site http://www.osti.gov/contact.html

This report was prepared as an account of work sponsored by an agency of the United States Government. Neither the United States Government nor any agency thereof, nor any of their employees, makes any warranty, express or implied, or assumes any legal liability or responsibility for the accuracy, completeness, or usefulness of any information, apparatus, product, or process disclosed, or represents that its use would not infringe privately owned rights. Reference herein to any specific commercial product, process, or service by trade name, trademark, manufacturer, or otherwise, does not necessarily constitute or imply its endorsement, recommendation, or favoring by the United States Government or any agency thereof. The views and opinions of authors expressed herein do not necessarily state or reflect those of the United States Government or any agency thereof. 


\section{CONTENTS}

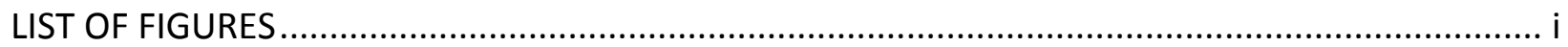

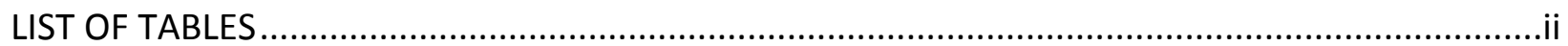

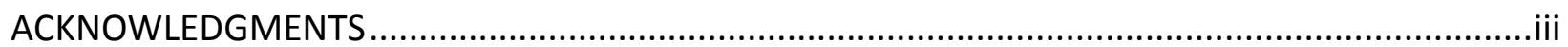

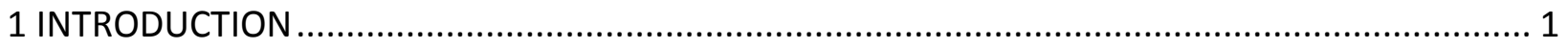

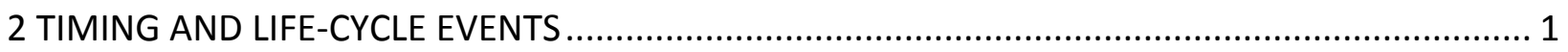

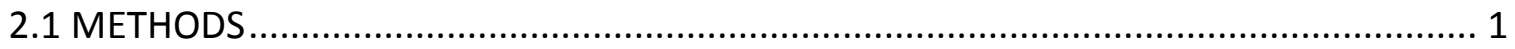

2.1.1 Distribution of redds in space and time ................................................... 1

2.1.2 Development of early lifestages................................................................ 2

2.2 LITERATURE REVIEW ................................................................................... 2

2.2.1 Distribution of redds in time and space ................................................. 2

2.2.2 Development of early lifestages............................................................... 4

2.2.3 Models of development from egg to fry ...................................................... 4

2.2.4 Models of development from fry to smolt................................................. 5

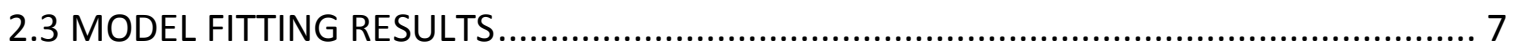

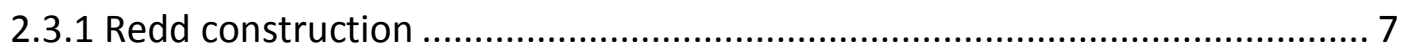

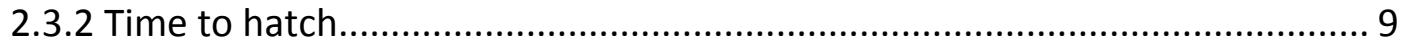

2.3.3 Time hatch to emergence .................................................................... 9

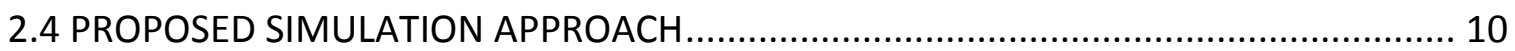

2.4.1 Distribution of redds in space and time .................................................... 10

2.4.2 Development of early lifestages................................................................. 10

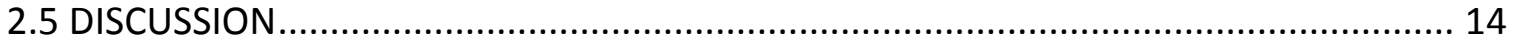

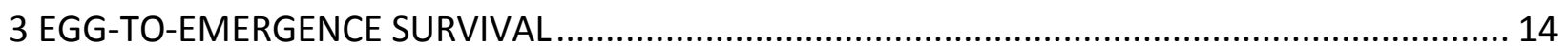

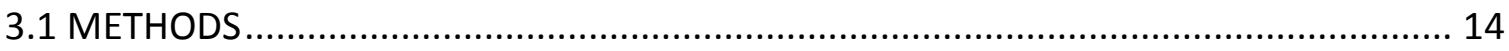

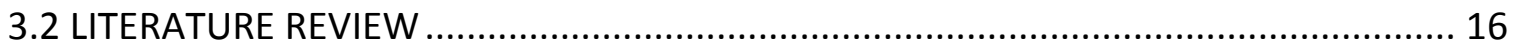

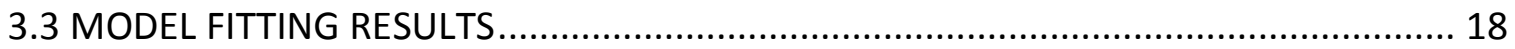


3.4 PROPOSED SIMULATION APPROACH.

3.5 DISCUSSION

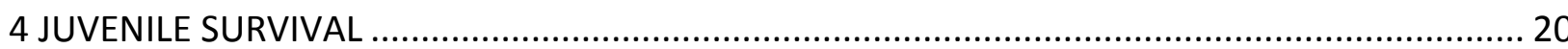

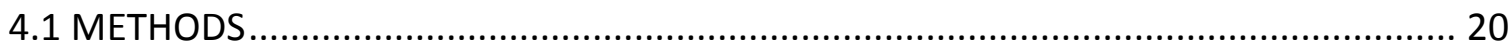

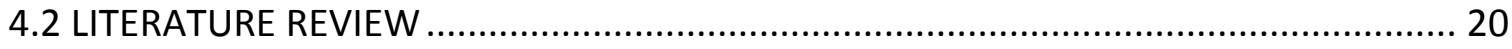

4.3 REVIEW OF SIMULATION APPROACHES ............................................................. 22

4.3.1 Empirical models based on field studies ............................................. 22

4.3.2 Risk assessment models based on laboratory studies ............................... 23

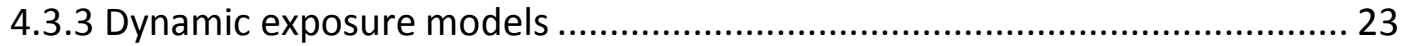

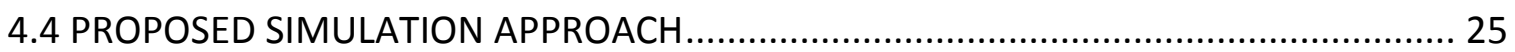

4.4.1 Logistic survival model with duration ............................................... 25

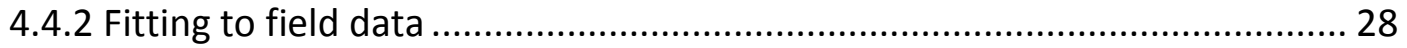

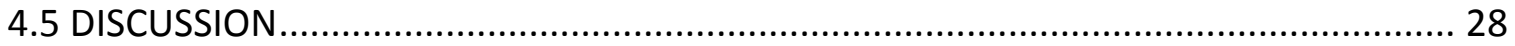

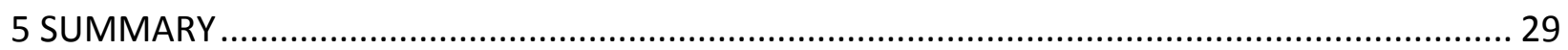

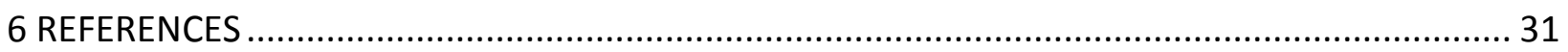

APPENDIX A. R-code to fit survival models as a function of incubation temperature............... 35

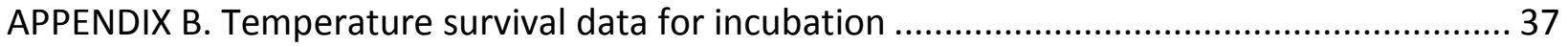




\section{LIST OF FIGURES}

Figure

Page

FIGURE 1. COMPARISON OF PREDICTED REDD COUNTS USING THE POISSON REGRESSION MODEL AND ACTUAL REDD COUNTS FOR EACH OF THE THREE TRIBUTARIES.

FIGURE 2. COMPARISON OF THE ALDERDICE \& VENSEN MODEL AND 2-PARAMETER MODELS FOR DEVELOPMENT TO HATCHING. DATA VALUES ARE SHOWN BY RED SQUARES.

FIGURE 3. COMPARISON OF MEASURED HATCH TO EMERGENCE TIMES (GREEN TRIANGLES) AND A FITTED EXPONENTIAL FUNCTION OF TEMPERATURE (RED SQUARES).

FIGURE 4. FLOW CHART FOR ALGORITHM TO ESTIMATE DEVELOPMENT AND EARLY SURVIVAL OF FALL CHINOOK SALMON FOR WEEK, LOCATION COHORTS.

FIGURE 5. MODELED DAILY SURVIVAL FITTED TO DATA FROM STUDIES OF FALL CHINOOK SALMON EGGS AND ALEVIN COMPARED WITH EXPERIMENTAL DATA.

FIGURE 6. DURATION-EXPOSURE CURVES FOR FALL CHINOOK SALMON FITTED BY SULLIVAN ET AL. (2000) TO UNPUBLISHED DATA COLLECTED BY BLAHM \& MCCONNELL (1970).

FIGURE 7. LOGISTIC RELATIONSHIP BETWEEN JUVENILE FALL CHINOOK SALMON SURVIVAL AND WATER TEMPERATURE WITH DURATION EFFECTS ESTIMATED EITHER A) USING DURATION-SPECIFIC THRESHOLDS OR B) BY ASSUMING MULTIPLICATIVE SURVIVAL AS IN S $S_{1, N}$. 


\section{LIST OF TABLES}

Table

Page

TABLE 1. ESTIMATED COEFFICIENTS FOR A POISSON REGRESSION FOR CHINOOK SALMON REDD COUNTS IN THREE TRIBUTARIES OF THE SAN JOAQUIN RIVER.

TABLE 2. ACCUMULATED THERMAL UNITS (DEGREE-DAYS ${ }^{\circ} \mathrm{C}$ ) AND DAYS REQUIRED FOR CHINOOK SALMON TO DEVELOP FROM ONE LIFE INTERVAL TO ANOTHER. RANGES ARE IN PARENTHESES.

TABLE 3. STUDIES OF SURVIVAL FOR EGGS, ALEVIN, AND JUVENILE FALL CHINOOK SALMON.

TABLE 4. PROPOSED VALUES FOR PARAMETERS OF DOUBLE WEIBULL FUNCTIONS TO DESCRIBE SURVIVAL. EXPONENTS KL AND KU MUST BE ODD INTEGERS.

TABLE 5. DIFFERENCE IN TWO ESTIMATES OF DURATION INFLUENCE ON LOGISTIC SURVIVAL: MULTIPLICATIVE HOURLY SURVIVAL MINUS SURVIVAL USING DURATION-SPECIFIC LC THRESHOLDS. 


\section{ACKNOWLEDGMENTS}

This research was funded Work for Others Agreement NFE-08-01729 entitled "CDFG San Joaquin River Fall-run Chinook Salmon Production Model Refinement" with AD Consultants by Oak Ridge National Laboratory (ORNL), managed by UT-Battelle, LLC for the U. S. Department of Energy under Contract No. DE-AC05-00OR22725. The author thanks Dean Marston (California Fish and Game), Carl Mesick (USFWS, retired), and Phil Groves (Idaho Power Company) for sharing important and relevant reports documenting incubation experiments and attempts to develop dynamic models of juvenile temperature stress. In addition, Dr. Mark Bevelhimer, an expert in modeling thermal effects on salmonids, provided a collegial review of this report. 


\section{INTRODUCTION}

The thermal regime of rivers has been altered by human activities (Caissie 2006).

Understanding the influences of these changes on aquatic biota is important so that appropriate management strategies can be devised. This report reviews literature pertaining to relationships between water temperature and fall Chinook salmon. Empirical models, developed from multiple sources of data, are also presented. Some of these may be incorporated into salmon population models such as the San Joaquin Fall Chinook Salmon model that is currently in development. The report is organized into three sections. The first section deals with the effects of temperature on the distribution of redds and the subsequent timing and development of freshwater life stages. The second section deals with temperature effects on survival of eggs and alevins. The third section treats temperature effects on juvenile survival.

\section{TIMING AND LIFE-CYCLE EVENTS}

\subsection{Methods}

\subsubsection{Distribution of redds in space and time}

The "initial conditions" for any model of salmon development are set by the event of spawning in a "redd" or nest. High temperatures may prevent upmigration by adult female spawners, and delayed effects on egg and alevins survival are a concern. I reviewed the literature related to temperature requirements for upmigration and effects on offspring survival to see whether these effects can be quantified.

I also conducted a preliminary statistical analysis of redd timing and spatial distribution in the three tributaries to the San Joaquin River, the Merced, Stanislaus, and Tuolumne rivers. The purpose of this analysis was to produce a statistical model describing the spatial distribution of redds constructed in the Merced, Stanislaus, and Tuolumne rivers. I combined data from salmon redd carcass surveys conducted by the California Department of Fish and Game between 1998 and 2008 for the three tributaries with data on redd location, year and Julian date of construction, flow and average water temperature. An evaluation of the distributions of all covariates indicated that only the redd count showed a significant deviation from normal. Log-transformed redd counts were used to construct Poisson regression relationships.

To begin with, an exploratory analysis using non-linear regression was conducted for a full model that included two indicator variables for the Merced $(\mathrm{Im})$ and Stanislaus (Is) rivers, all linear terms, quadratic terms for temperature $(T)$, flow $(Q)$, Julian date $(J)$, upstream distance in 
river $\mathrm{km}(\mathrm{Rkm})$, and interactions between $\mathrm{Im} \times \mathrm{Rkm}, \mathrm{J}$ and $\mathrm{T}, \mathrm{J}$ and Rkm. Pairwise correlations between estimates of linear parameter estimates were not high enough to raise concerns. The full model explained $39.57 \%$ of variation $\left(\operatorname{adj~} R^{2}\right.$ ). Three coefficient estimates not significantly different from zero (alpha $=0.1$ ) were $\mathrm{Im}, \mathrm{T}, \mathrm{J} \times \mathrm{T}$.

The model above did not consider autocorrelation in carcass counts. In addition, count data are more-appropriately modeled using Poisson regression. This was addressed by fitting a full Poisson regression with two key features: 1) a log-link function with overdispersion in count variances and 2) compound-symmetric correlations for counts within the same river and year. It was not possible to fit the correlation structure, so modeling proceeded under the assumption of independence among years, but included year (time) and river (space) as predictors, thus treating these as deterministic effects.

\subsubsection{Development of early lifestages}

I reviewed the literature describing the time required to transition through each of two developmental stages: egg incubation to hatching and hatching (alevins) to emergence as fry. Egg and alevin development has typically been studied under laboratory conditions with constant temperatures. Laboratory studies report development times in days for different temperature treatments from fertilization of eggs to $50 \%$ egg hatch and to $50 \%$ emergence from redds as fry (this marks the transition from the larval alevin life interval to the fry life interval). Efforts were made to keep temperatures for each treatment constant, and an average is usually reported. In constant-temperature settings, the number of accumulated thermal units (ATUs) is calculated by multiplying the average treatment temperature by the number of days in the life interval.

Duration of each life stage increases as temperature decreases. I fitted exponentially increasing relationships between duration $(\mathrm{d})$ and temperature $\left({ }^{\circ} \mathrm{C}\right)$ using data from five studies for egg incubation (Garling and Masterson 1985; Murray \& Beacham 1988; Beacham \& Murray 1990; Heming 1982; Jensen and Groot 1990).

\subsection{Literature review}

\subsubsection{Distribution of redds in time and space}

According to Yates et al. (2008), upstream migration stopped in the San Joaquin River when water temperature exceeded $21^{\circ} \mathrm{C}$, but resumed when the water temperature fell to $18.3^{\circ} \mathrm{C}$ (DWR 1988). In the lower Columbia River, Goniea et al. (2006) found that migration rates slowed significantly at temperatures above $20^{\circ} \mathrm{C}$. During these times, adults sought thermal refuge in tributaries, which averaged $2-7^{\circ} \mathrm{C}$ cooler than the mainstem. Migration was also inhibited in the Klamath River basin at temperatures from 21.8 to $24.0^{\circ} \mathrm{C}$ ( mean $=22.9^{\circ} \mathrm{C}$ ) 
(Strange 2010). Strange proposed daily average or weekly maximum temperatures of $23^{\circ} \mathrm{C}$ or weekly average of $22^{\circ} \mathrm{C}$ as upper thermal limits for migration. Oxygen depletion $(<4 \mathrm{mg} / \mathrm{L})$, when combined with high temperatures, is more likely to block migration than temperature alone (Hallock et al. 1970; Sams and Conover 1969, both reviewed in Groves et al. 2007).

Pre-spawning exposure of adults to high temperatures has been cited as a cause for elevated mortality, both of parents and of eggs during incubation. According to a review by Groves et al. (2007), pertinent literature describing pre-spawn mortality of adults is based on holding of hatchery broodstock of spring or summer Chinook salmon. The mechanism for broodstock deaths, in most cases, was the outbreak of disease caused by long exposure times. Groves et al reported that Bergman (1990) had no trouble maintaining adult spring Chinook for 15 days or longer at temperatures near $19^{\circ} \mathrm{C}$, but higher temperatures would likely have adverse effects.

Gamete viability following maternal exposure to elevated temperatures is very difficult to study, and this has prevented the detection or quantification of relationships between offspring survival and parental temperature exposure. The literature reviewed by Groves et al. suggests that the best support for such an effect comes from a study by Jensen et al., and other commonly-cited sources do not stand up to scrutiny (e.g., Hinze et al. 1956, 1959). For example, a study by Berman (master's thesis 1990) resulted in deaths of 15 of 20 adult spring Chinook salmon held at elevated temperatures $\left(19^{\circ} \mathrm{C}\right)$ due to Columnaris disease.

Consequently, temperatures were reduced for the survivors. Although pre-hatch egg mortality was reported to be higher in eggs extracted from five females reared at higher temperatures than in eggs extracted from two females raised at lower temperatures, no statistical tests were presented. The experiment was terminated when chlorine killed alevins in all treatments and it was not possible to compare survival to emergence for the two groups.

In a second thesis, Mann (2007) tracked females with internal temperature monitors implanted after passing above the first dam on the Snake River, Idaho. Although adults that encountered more degree-days above $20^{\circ} \mathrm{C}$ were more likely to reach spawning areas, embryo mortality was not elevated. The highest mortalities were in offspring of adults that encountered zero degreedays above $20^{\circ} \mathrm{C}$. Another interesting finding of this study was the frequency with which falland summer-run adult Chinook salmon encountered temperatures above $22^{\circ} \mathrm{C}$.

Jensen et al. (2006) studied summer Chinook salmon from the Puntledge River, Canada under three different temperature regimes. Despite similar maturation rates, pre-spawning mortality was significantly higher for the group held at highest temperatures (average $17-19^{\circ} \mathrm{C}$; maximum daily average of $\left.22^{\circ} \mathrm{C}\right)$ than for the group held at the lowest temperatures $\left(8-9^{\circ} \mathrm{C}\right)(57 \%$ vs. $8 \%$ mortality). Eggs from females in the coolest and warmest holding ponds were then incubated in the same environment. Eggs from females in the coolest holding pond had a lower mortality rate $(3 \%)$ than those from females held at the other two facilities ( $12 \%)$.

Several factors can reduce the risk to spawners and to their eggs caused by pre-spawn exposure to high water temperatures in a natural river environment. First, behavioral thermoregulation 
in deep pools, tributaries, or groundwater upwelling areas may be possible. Thermoregulation by swimming at depths in Snake River reservoirs has been documented (Mann 2007). Secondly, high temperatures in early fall decline as the season progresses, which likely reduces the duration of parental exposure to elevated temperatures (see Groves et al. 2007).

\subsubsection{Development of early lifestages}

No studies of incubation and emergence timing have been conducted with Central Valley stocks (Myrick and Cech 2004). Alderdice \& Velsen (1978) compiled data from early studies and developed a model of development, which we present below. These data are not described in detail and it is uncertain whether the stocks are fall Chinook. Garling and Masterson (1985) reported development times for Chinook salmon in the Great Lakes. Three rigorous studies were conducted with fall Chinook stocks from Fraser River tributaries in British Columbia (Murray \& McPhail 1988; Beacham \& Murray 1990; Jensen \& Groot 1991). The Jensen and Groot study also examined the effects of dewatering on incubation times and survival.

Two recent incubation studies were conducted in the Columbia River Basin. Geist et al. (2006) examined the effects of both natural (variable) temperature regimes and dissolved oxygen on Columbia River fall Chinook, finding developmental delays among eggs exposed to low dissolved oxygen levels. Geist et al. (2006) reported that 535 ATU are required to hatch under natural thermal regimes and another 409 ATU to reach emergence, values consistent with those of Murray and McPhail (1988). Connor et al. (2003) estimated that 1,066 ATU were required from fertilization to emergence in Snake River stocks. This estimate is higher than other reported values because emerging fry were required to ascend through $7 \mathrm{~cm}$ of gravel. The Connor et al. estimate provides a better representation of field conditions experienced during the alevin stage, suggesting that an additional 122 ATU are needed to navigate up through gravels.

The process of developing from fry to smolt is well-studied in terms of physiology, but a detailed physiological approach is not needed to represent its demographic relevance in terms of timing and survival of individuals. The time of entry to seawater is a critical period, and larger juveniles are more likely to survive the parr-smolt transformation. Juvenile fall Chinook salmon $1.5 \mathrm{~g}$ and larger are capable of tolerating seawater and growing after transfer, reaching optimal adaptability at 5 to $6 \mathrm{~g}$ (Clark and Shelbourne 1985).

\subsubsection{Models of development from egg to fry}

Simple models of time to hatch and emergence have been developed that can predict timing based on temperature for incubation temperatures above $5^{\circ} \mathrm{C}$ (Crisp 1988, Alderdice and Vensen 1978). Several studies have reported that temperatures less than $5^{\circ} \mathrm{C}$ contribute less than higher temperatures (Alderdice \& Velsen 1978; Beacham and Murray 1990, Connor et al. 2003), and it has been suggested that these should be down-weighted by approximately one- 
half.

Alderdice and Vensen (1978) proposed the Belehradek model below for various races of Chinook salmon. This model is fit using linear regression between $\log _{\mathrm{e}}$-transformed rate of development, which they defined as $100 /$ days to hatch, and $\log _{\mathrm{e}}$-transformed temperature in ${ }^{\circ} \mathrm{C}$.

$$
\text { Days to hatch }=\frac{100}{0.08646(T+2.26721)^{1.23473}}
$$

In addition to temperature, dissolved oxygen can have important effects on development rates. Geist et al. (2006) found that Snake River fall Chinook salmon eggs required 6-10 d longer to hatch and $24 \mathrm{~d}$ longer to emerge at $4 \mathrm{mg} \mathrm{L}^{-1}$ than at saturation. They developed equations (Equation 2) under natural, variable thermal regimes, where initial temperature $\mathrm{T}$ is in ${ }^{\circ} \mathrm{C}$ and $\mathrm{DO}$ is in $\mathrm{mg} \mathrm{L}^{-1}$. Dissolved oxygen in water when saturated is a function of temperature and tabulated values are readily available.

$$
\begin{aligned}
& \text { Days to hatch }=146.8-5.5 T-1.76 \mathrm{DO} \\
& \text { Days hatch to emergence }=327-10.1 \mathrm{~T}-4.24 \mathrm{DO}
\end{aligned}
$$

This relationship would be difficult to use in practice because the variation in water temperature encountered in the field will not track that in their experiments. However it does provide an idea of how spawning date might influence incubation. Because of their linear form, the relationships might not perform well at low temperatures. Future efforts to integrate DO into the general model would be useful, particularly if thermal units were used as a predictor in the model instead of initial temperature.

I fitted the following power model to 22 measurements reported by five studies of fall Chinook salmon eggs using temperatures ranging from 1.5 to $20^{\circ} \mathrm{C}$, fixing the offset to the value of Alderdice \& Vensen:

$$
\text { Days to hatch }=7.3228(T+2.2672)^{-1.34185}
$$

\subsubsection{Models of development from fry to smolt}

Development from fry to smolt can be predicted using approaches ranging from simple to complex. The simplest approach is to predict growth and development to the point of smoltification based on ATU (degree-days). According to Shrimpton et al. (2007), the number of degree days has been shown to be linked to physiological and behavioral changes associated 
with smolting, regardless of whether temperatures were fluctuating or constant. Shrimpton et al. found that the degree-days required to develop into a smolt from emergence (ponding) was 1,185 ATU. EBMUD (1992) estimated that 1,082 ATU are required for emerging fry to reach the smolt stage in the Mokelumne River, California. Empirical modeling of rotary screw-trap data in the Tuolumne River suggested that degree-days were the best predictor of outmigration, and the maximum date occurred at 1,562 ATU (Jager and Sale 2006). However, note that relying on ATUs assumes a positive relationship between the rate of development and temperature, which may be violated at high extreme temperatures. The approach could potentially be modified to discount extreme high temperatures.

Bioenergetic models offer a second common approach to simulating growth and development. Typically fall Chinook begin the smoltification process after reaching a certain size, and thus it is reasonable to assume that development is predicted by growth. Examples of bioenergetics models for Chinook salmon are common (e.g., Jager et al. 1997), but the supporting data are rare. The underlying parameter values derive from the same handful of studies, in some cases from related species in very different habitats (e.g., Chinook salmon in the Great Lakes, sockeye salmon in British Columbia, rainbow trout, brown trout) suggesting that more research to obtain species-specific bioenergetics data may be needed. In the Central Valley, it is fortunate that data describing respiration costs and growth for California stocks was collected by Myrick (1999). A recently developed bioenergetic model that used California data to the extent possible (Jager 2011) is described below.

"The juvenile growth model simulates the growth of each quantile cohort from emergence until fry became smolt and leave the tributary. The simulated growth rate of juveniles depends on temperature, fish size, and ration. Daily growth, $\Delta W$ (g wet weight), is

$$
\begin{aligned}
& W(t+1)=W(t)+\Delta W, \\
& \Delta W=C-E p \cdot C-R,
\end{aligned}
$$

where $C$ = daily consumption and $R=$ standard + active respiration. Elliott (1976) observed that three energetic costs: egestion, excretion, and specific dynamic action (cost associated with digestion) varied widely as individual components, but tended to sum to $40 \%$ of consumption, $E p=0.4$. Consumption is modeled as a uni-modal function of temperature, $f(T)$ and fish weight, $W$ in $g$. Three parameters in $f(T)$ were fitted to bioenergetics data for Central Valley fall Chinook (Myrick 1999; Myrick and Cech 2002).

$$
C=p C_{\max } ; C_{\max }=c a W^{c b} f(T)
$$

To estimate growth in length from growth in weight, expected length, $L(\mathrm{~mm})$, was estimated from an allometric relationship with weight. In days when the length of juvenile salmon in a quantile-cohort fell below that expected based on their weight, length 
was increased to that expected."

Myrick reported consumption and growth at maximum feeding levels and at $25 \%$ of maximum ration for three temperatures, 11,15 , and $19^{\circ} \mathrm{C}$. He also reported standard or routine respiration at $19^{\circ} \mathrm{C}$ for both rations. The standard bioenergetics model, as described in Equations 4 and 5 with $c a=0.35$, resulted in negative growth at $25 \%$ of maximum ration and positive growth at $100 \%$ of maximum ration, but the predicted growth and conversion efficiencies at high ration were lower than those measured by Myrick (1999).

\subsection{Model fitting results}

\subsubsection{Redd construction}

Models to predict the number of redds constructed in space and time included water temperature as a covariate. Statistics for the full model with 1453 observations were Akaike's Information Criterion $(\mathrm{AICC})=1660.4$, Bayes Information Criterion $(\mathrm{BIC})=1744.9$, and scaled deviance = 1437 with 1437 degrees of freedom. The Stanislaus River had a higher intercept and a different interaction with river $\mathrm{km}$ than the other two tributaries. I compared the full model with a reduced model that retained only statistically significant variables $(\propto=0.1)$, removing $\mathrm{Im}, \mathrm{J} \times \mathrm{T}, \mathrm{Rkm}{ }^{2}, \mathrm{Q} \times \mathrm{T}$, and $\mathrm{Q}^{2}$. Statistics for this reduced Poisson regression model were scaled deviance $=1444$ with 1444 degrees of freedom, $\mathrm{AICC}=1648.1$, and $\mathrm{BIC}=1695.6$. These values are lower than those of the full model, suggesting the trade-off between parsimony and fit is better in the reduced model. In the final model, correlation structure was removed because estimates suggested it was not important.

The final model showed a significant negative trend across years, quadratic relationships with Julian date and temperature, and a positive effect of upstream distance (Table 1). Redd counts showed a positive relationship with upstream distance in rivers other than the Stanislaus (Table 1). Statistics for this reduced Poisson regression model with no correlation structure were scaled deviance $=1445$ with 1445 degrees of freedom. The scale estimate (Table 1$)$ indicates that counts were overdispersed. 
Table 1. Estimated coefficients for a Poisson regression for Chinook salmon redd counts in three tributaries of the San Joaquin River.

\begin{tabular}{|l|l|l|l|l|}
\hline Parameter & Description & Estimate & $\begin{array}{l}\text { Wald } \\
\text { Chi-square }\end{array}$ & Pr $>\mathrm{X}^{2}$ \\
\hline Intercept & & 83.4736 & 9.43 & 0.0021 \\
\hline Rkm & Distance upstream (rkm) & 0.1375 & 224.0 & $<0.0001$ \\
\hline Is & $\begin{array}{l}\text { = Stanislaus River 0=Merced or Tuolumne } \\
\text { R. }\end{array}$ & 4.8896 & 67.05 & $<0.0001$ \\
\hline Rkm x Is & River - Rkm interaction & -0.1080 & 80.26 & $<0.0001$ \\
\hline Year & Year & -0.1439 & 210.42 & $<0.0001$ \\
\hline $\mathrm{J}$ & Julian date & 1.0715 & 251.94 & $<0.0001$ \\
\hline $\mathrm{T}$ & Average daily $\left({ }^{\circ} \mathrm{C}\right)$ & 1.4899 & 6.38 & 0.0115 \\
\hline $\mathrm{T}^{2}$ & Squared temperature & -0.0138 & 6.90 & 0.0086 \\
\hline $\mathrm{J}^{2}$ & Squared date & -0.0018 & 254.48 & $<0.0001$ \\
\hline Scale & & 6.2320 & & \\
\hline
\end{tabular}

To evaluate goodness-of-fit, Pearson's correlations, $R$, between predicted and observed redd counts are presented (Figure 1). Correlations between observed and predicted redd counts were lower for the Merced $(R=0.5394, N=479)$ and Stanislaus rivers $(R=0.5067, N=466)$ than for the Tuolumne River $(R=0.7403, N=508)$. Because quadratic relationships were found between redd count and date and between redd count and temperature, it should be possible to estimate an optimal date and temperature for spawning for a given river, year, and distance upstream.

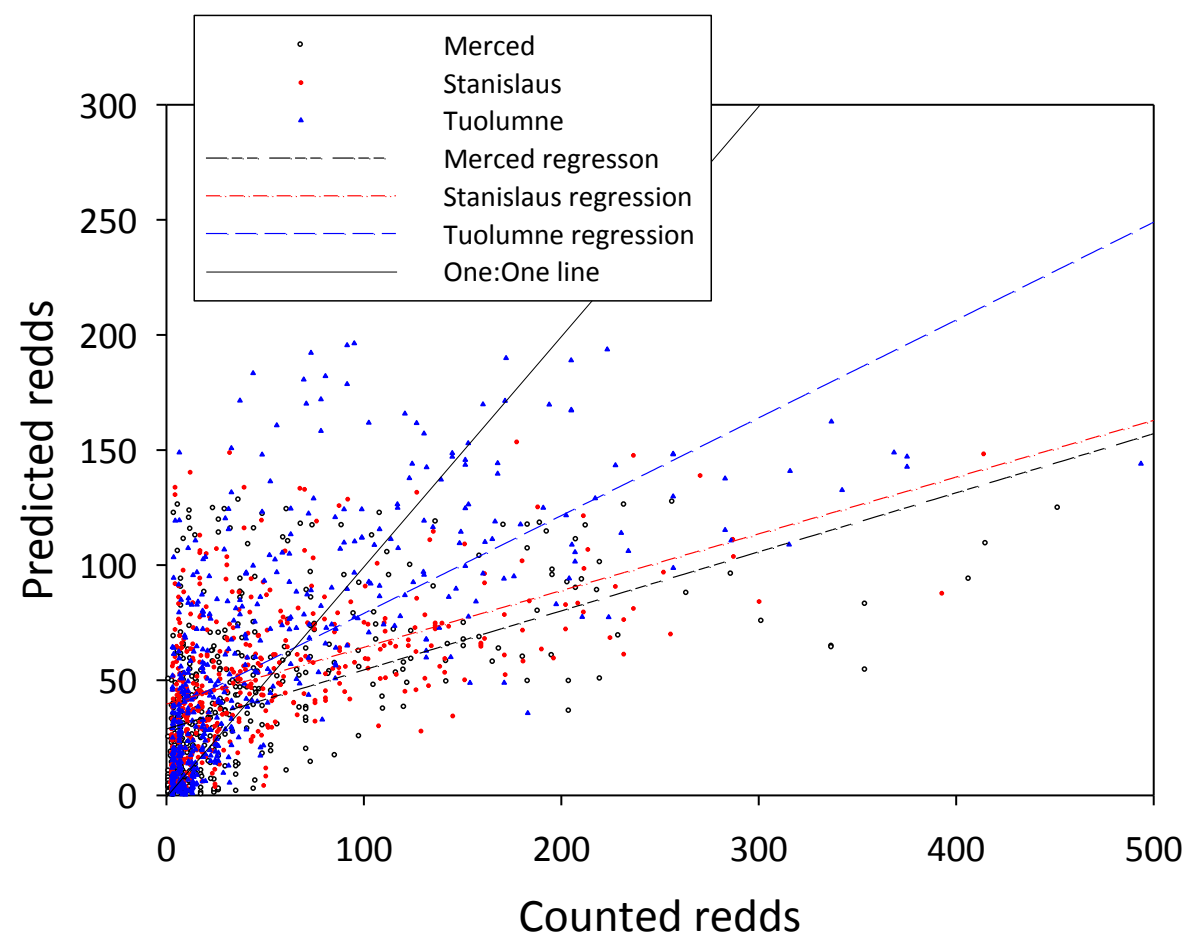

Figure 1. Comparison of predicted redd counts using the Poisson regression model and actual redd counts for each of the three tributaries. 


\subsubsection{Time to hatch}

I compared several linearizable 2-parameter models for hatching time, a power model, exponential model, and a power model using the Alderice \& Vensen temperature offset (2.2672 ${ }^{\circ} \mathrm{C}$ ). All models performed well for temperatures exceeding $2^{\circ} \mathrm{C}$, but Alderdice $\&$ Vensen's Belehradek model fit the lowest temperature best (Figure 2). Among models that were fitted to compiled data, the one with the highest adjusted $R^{2}$ was the power model with the fixed offset (Equation 3, $p<0.0001, d f=21$, adj. $R^{2}=0.972, \mathrm{MSE}=0.091$ ). The correlation between observed and predicted days to hatch was 0.9826 using the 2-parameter power model, 0.9961 using the power model with offset, and 0.9970 for the Belehradek model $(\mathrm{N}=22)$.

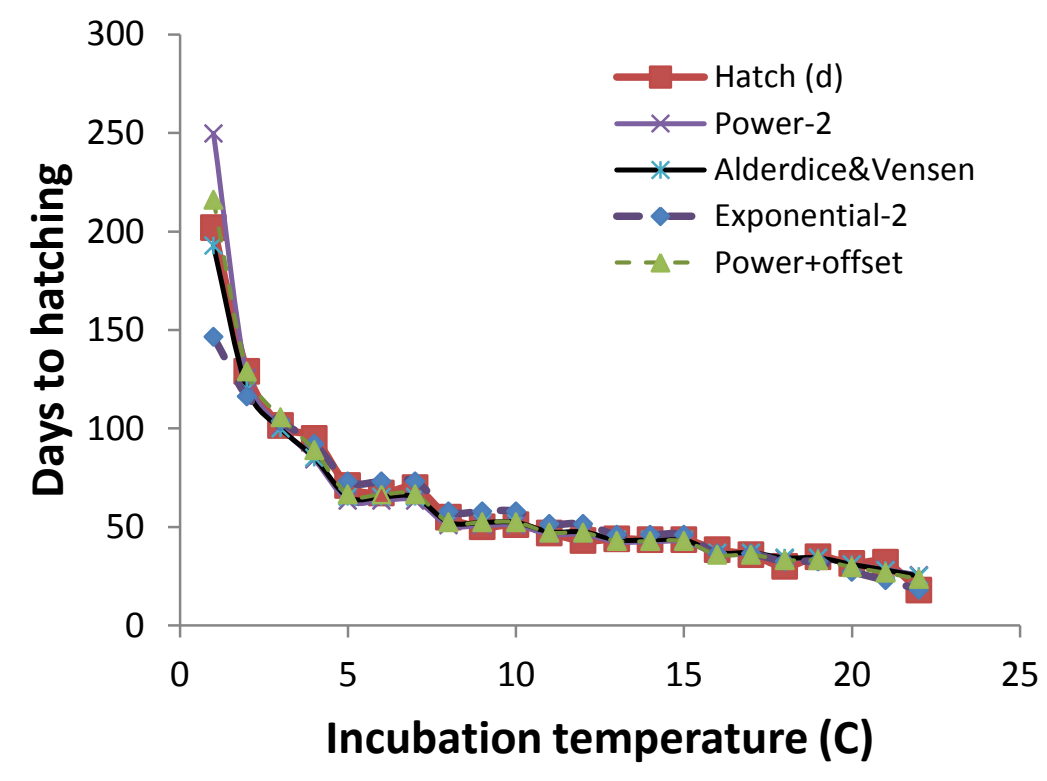

emergence
Figure 2. Comparison of the Alderdice \& Vensen model and 2-parameter models for development to hatching. Data values are shown by red squares.

\subsubsection{Time hatch to}

I fitted a 2-parameter exponential model for emergence to a smaller compiled dataset that included temperatures ranging from 2 to $15^{\circ} \mathrm{C}$ (Equation $6, \mathrm{p}<0.0001$, adj. $\mathrm{R}^{2}=0.965, \mathrm{df}=8$ ). This exponential model fitted better than did a power model (Figure 3 ).

Days hatch to emergence $=139.65 e^{-0.11873 T}$ 


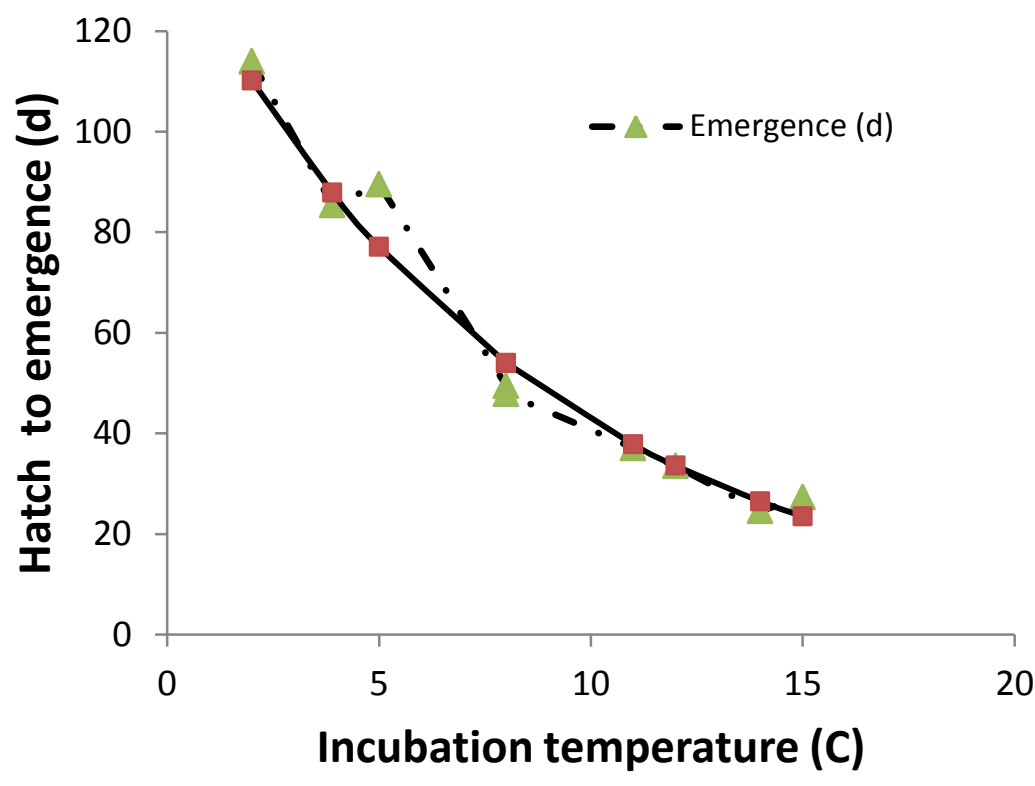

Figure 3. Comparison of measured hatch to emergence times (green triangles) and a fitted exponential function of temperature (red squares).

\subsection{Proposed simulation approach}

\subsubsection{Distribution of redds in space and time}

To model the distribution of redds in space and time requires conditional estimates of the proportion of female spawners on each date and in each reach from a total by river that can be drawn from a multinomial distribution. This could then be used to distribute spawners in the model, given an annual total that is derived from the ocean sub-module. The analysis presented here can be improved by using proportions and a distribution-fitting paradigm, possibly using a bivariate Gaussian distribution with respect to date and river $\mathrm{km}$. In place of using "year" as a predictor, perhaps downstream water temperatures in the lower San Joaquin River could be included as a way to represent delays in upmigration, i.e., as an offset for the distribution with respect to Julian date.

\subsubsection{Development of early lifestages}

Two different approaches can be used to simulating temperature-driven development. In an individual-based and spatially explicit model for fall Chinook salmon (ORCM), we simply compared accumulated degree days against threshold values, discounting low temperatures by half (Jager et al. 1997). Literature values for degree-days are summarized for fall Chinook salmon in Table 2. In our white sturgeon PVA model (Jager et al. 2002), days to hatch and emergence were updated dynamically using a relationship of the form $Y(h)=a e^{b T}$ that was parameterized by lab experiments. Spawning of individuals was simulated over a distribution of times and for each individual female fish, development from one stage to the next was 
simulated by accumulating fractional development $1 /$ Ndays, where number of days, Ndays $=$ 24/1535.6 $\mathrm{e}^{-0.071 \mathrm{~T}}$ was based on the current temperature, $\mathrm{T}$ (Figure 4). The individual would then graduate to the next stage when this sum exceeded 1. This incubation model was run separately from the main PVA model and used to estimate survival for different types of hydrologic year types (wet, normal, dry).

For a weekly model, I recommend the second approach above to estimate survival through egg and alevin life stages for weekly cohorts as a function of daily temperatures, as outlined by Figure 4. Given a distribution of spawners over weeks and river segments, cumulative development for each cohort $j, s$ can be tracked over time as a sum of fractional development (adding one day of the total required at today's temperature, where the total required varies with temperature as described by Equation 1 for eggs and Equation 3 for alevins). Cumulative fractional development of eggs is given by Equation 7 below.

$$
\text { CumEggDev }_{j, s, w}=\sum_{w=1}^{T^{w}} \sum_{d=1}^{7}\left(\frac{1}{2.282\left(T_{r(j, s), d}+2.26721\right)^{0.7402}}\right),
$$

where $r(j, s)$ is the location of cohort $j, s$ in week $w$ and $T$ is daily water temperature in ${ }^{\circ} \mathrm{C}$. When CumEggDev, which is a cohort attribute, exceeds one, then the cohort progresses to the alevin life interval. Likewise, Equation 8 describes development of alevins.

$$
\operatorname{CumAlvDev}_{j, s, w}=\sum_{w=1}^{T^{w}} \sum_{d=1}^{7}\left(\frac{1}{139.65 \exp ^{-0.11878 T_{r(j, s), d}}}\right),
$$

The two equations above determine the life stage that a given cohort belongs to on a given day(week), which is needed only because temperature-related survival is life-stage dependent. Life stage, $L$, is defined as a function of the two sums above.

$$
L_{j, s, w}=\left\{\begin{aligned}
\text { egg, CumEggDev } & \\
\text { alevin, CumEggDev }_{j, s, w} & >1, \text { CumAlvDev }_{j, s, w}<1 \\
\text { fry,CumAlvDev } & >1
\end{aligned}\right.
$$




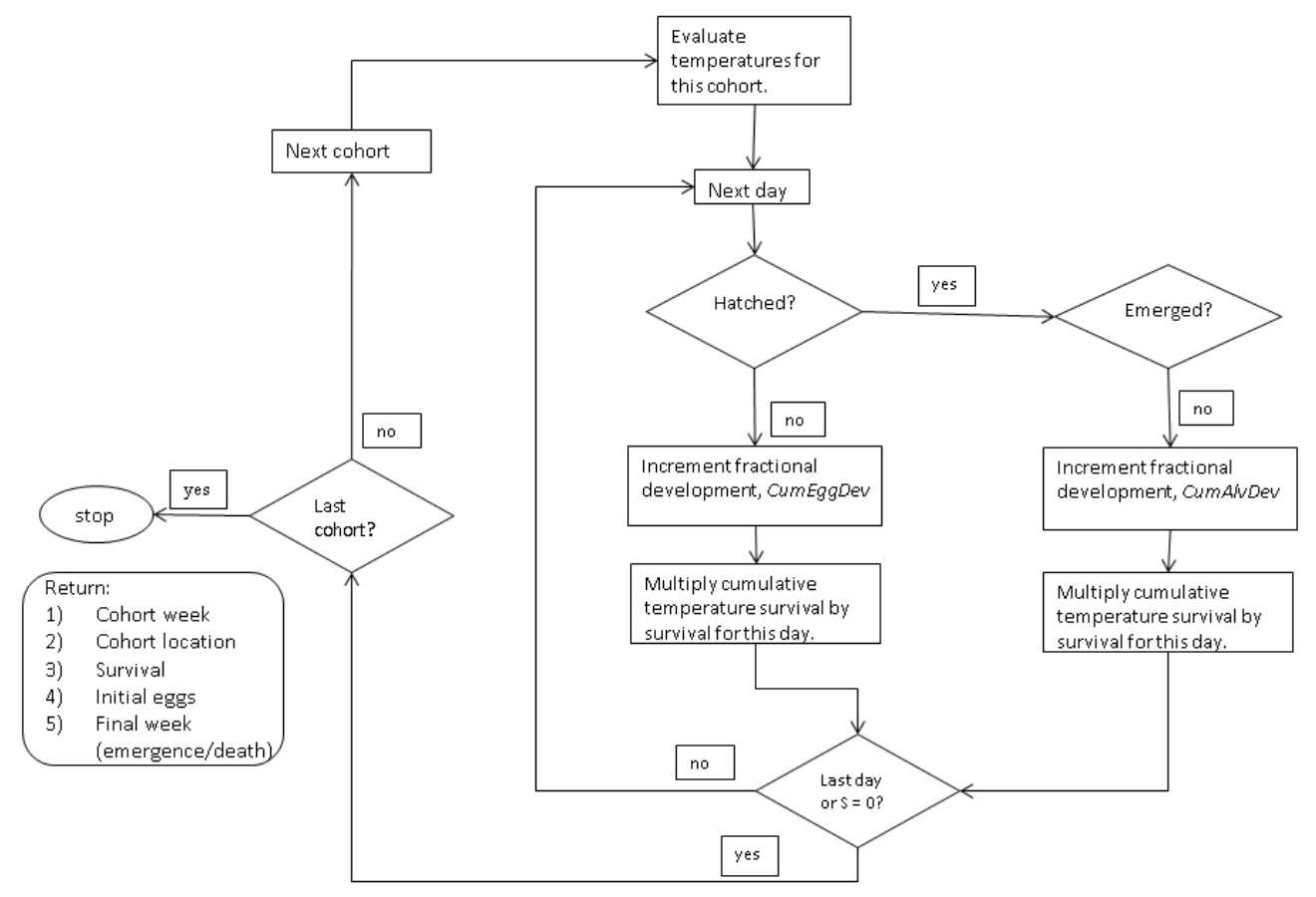

Figure 4. Flow chart for algorithm to estimate development and early survival of fall Chinook salmon for week, location cohorts. 
Table 2. Accumulated thermal units (degree-days ${ }^{\circ} \mathrm{C}$ ) required for Chinook salmon to develop from one life interval to another. Ranges are in parentheses.

\begin{tabular}{|c|c|c|c|c|}
\hline Source & Stock, location & Notes & $\begin{array}{l}\text { Egg fertilization to } 50 \% \\
\text { hatch (ATU) }\end{array}$ & $\begin{array}{l}\text { Egg fertilization to } \\
50 \% \text { emergence (ATU) }\end{array}$ \\
\hline $\begin{array}{l}\text { Murray \& } \\
\text { McPhail (1988) }\end{array}$ & $\begin{array}{l}\text { Fall Chinook, } \\
\text { British Columbia }\end{array}$ & & 500 & $500+395.8$ \\
\hline $\begin{array}{l}\text { Garling \& } \\
\text { Masterson } \\
(1985)\end{array}$ & $\begin{array}{l}\text { Fall Chinook, Great } \\
\text { Lakes }\end{array}$ & $\begin{array}{l}\text { Constant regimes, three } \\
\text { temperatures } \\
\text { Note: published days to hatch are } \\
\text { reversed (that reported for } 9.9 \mathrm{C} \text { is } \\
\text { switched with that for } 15 \mathrm{C} \text { ). }\end{array}$ & $\begin{array}{l}482 \sim 50 \mathrm{~d} \times 9.9^{\circ} \mathrm{C} \\
488 \sim 43 \mathrm{~d} \times 11.4^{\circ} \mathrm{C} \\
450=30 \mathrm{~d} \times 15.0^{\circ} \mathrm{C}\end{array}$ & Not reported \\
\hline $\begin{array}{l}\text { Geist et al. } \\
(2006)\end{array}$ & $\begin{array}{l}\text { Fall Chinook, } \\
\text { Snake River, Idaho }\end{array}$ & $\begin{array}{l}\text { Natural thermal regime, saturated } \\
\text { DO }\end{array}$ & $\begin{array}{l}535(502-587) \\
\text { \#days = 146.8 - 5.5 T } \\
-1.76 \text { DO }\end{array}$ & $\begin{array}{l}944(868-1,001) \\
\text { \#days = 327 - } 10.1 \mathrm{~T} \\
-4.24 \mathrm{DO}\end{array}$ \\
\hline $\begin{array}{l}\text { Connor et al. } \\
(2003)\end{array}$ & $\begin{array}{l}\text { Fall Chinook, } \\
\text { Upper Columbia } \\
\text { R., OR strays into } \\
\text { Snake R.. }\end{array}$ & $\begin{array}{l}\text { Ascended through } 7 \mathrm{~cm} \text { gravel to } \\
\text { emerge. } \\
\text { Lower duration than is evidenced by } \\
\text { field data. }\end{array}$ & & $\begin{array}{l}\text { Average } 1,066 \pm 9, \\
\text { increased from } 1,056 \\
\text { ATU at } 4.5 \mathrm{C} \text { to } 1,079 \\
\text { ATU at } 8.4 \mathrm{C}\end{array}$ \\
\hline
\end{tabular}




\subsection{Discussion}

Distributing redds in space and time is an important link between the freshwater and ocean phases when modeling the full life cycle of a fall Chinook salmon population. A preliminary approach to modeling the distribution of redds in space and time was presented here. The model revealed a unimodal relationship between carcass counts/redd numbers and tributary temperature. This model will require further refinement. At this time, field and laboratory evidence for effects of maternal exposure to high temperature on incubation survival is too weak to consider in a quantitative modeling framework. One recommendation is to support research done by experienced scientists (i.e., not student theses) to quantify such a relationship if it exists, because of the many confounding factors to be controlled. It should be noted that the ability to avoid high temperatures is likely much lower in the San Joaquin River basin than in the Lower Columbia River basin. The issue of maternal exposure is more likely to be important for this extreme population than for populations farther north. Understanding thermal refuges is a critical, but understudied, area in salmon conservation.

This study included a meta-analysis and fitting of models describing survival of early lifestages as a function of temperature. The next step in this endeavor should be to evaluate these relationships for field studies under natural thermal regimes. In addition, models that incorporate \%fines, and groundwater influence (or characterize differences between temperatures in gravel and in overlying water) are needed.

\section{EGG-TO-EMERGENCE SURVIVAL}

\subsection{Methods}

I conducted a meta-analysis of studies describing survival through each of two developmental stages: egg incubation to hatching and hatching (alevins) to emergence as fry. In particular, I focused on studies that used constant-temperature treatments (Table 3). A critical review of these studies can be found in Groves et al. (2007).

Both the duration and survival through the two developmental stages depend on temperature. I tabulated survival from literature studies and standardized survival by dividing by the maximum survival over all temperature treatments. Survival to hatch and survival from hatch to emergence were converted to daily values using the days to hatch and emerge (see previous section) by raising survival through the period to the power, 1/duration (d). If the study did not report the duration of the two developmental stages, I used the temperature relationship fitted for the life stage (Equations 1 or 3 ) to estimate days. 
Table 3. Studies of survival for eggs, alevin, and juvenile fall Chinook salmon.

\begin{tabular}{|c|c|c|}
\hline Source & Stock, location & Notes \\
\hline Beacham \& Murray (1989) & $\begin{array}{l}\text { Fall Chinook, Quesnel, Kitimat \& Bella Coola } \\
\text { Rivers, British Columbia }\end{array}$ & $\begin{array}{l}8 \text { families, } 2 \text { replicates per family. Constant regimes, survival calculated } \\
\text { only on fertilized eggs, 703-2097 eggs / family (river). } \\
\text { No survival at } 2^{\circ} \mathrm{C} \text {. High temperatures not included. }\end{array}$ \\
\hline Combs \& Burroughs (1957) & Entiat, Skagit R, Washington USA & $\begin{array}{l}\text { Averages of results from } 1-4 \text { stocks, } 600-1,000 \text { eggs for each of } 10 \\
\text { constant temperatures } 1.583-15.556 \mathrm{C} \text {. } \\
\text { Reduced survival in trials with constant temp }<4^{\circ} \mathrm{C} \text {. } \\
\text { High (>=99\%) survival in egg experiments with low temperatures after } 1 \\
\text { month. }\end{array}$ \\
\hline Murray \& McPhail (1988) & $\begin{array}{l}\text { Fall Chinook (Aug-Sept spawners), Babine } \\
\text { Rivers, British Columbia }\end{array}$ & $\begin{array}{l}\text { Eggs from one female. } 600-1,000 \text { eggs per temperature for } 2,5,8,11 \text {, } \\
\text { and } 14 \mathrm{C} \text { treatments, no replicates. } \\
\text { Only fertilized eggs were counted in survival. } \\
\text { Survival declined below } 2^{\circ} \mathrm{C} \text { and above } 14^{\circ} \mathrm{C}\end{array}$ \\
\hline Garling \& Masterson (1985) & Fall Chinook, Great Lakes & $\begin{array}{l}\text { Constant regimes, three temperatures } \\
\text { Note: published days to hatch are reversed (that reported for } 9.9^{\circ} \mathrm{C} \text { is } \\
\text { switched with that for } 15^{\circ} \mathrm{C} \text { ). } \\
\text { Unfertilized eggs are included in survival. }\end{array}$ \\
\hline Jensen \& Groot (1991) & Fall Chinook, Nanaimo, British Columbia. & $\begin{array}{l}\text { Replicated (2-reps/temperature treatment), but small sample sizes ( 30 } \\
\text { eggs) } \\
\text { Purpose of study to examine moist-air incubation in hatcheries } \\
\text { Constant incubation temperatures }>14.3^{\circ} \mathrm{C} \text { resulted in higher mortality, } \\
\text { with complete mortality at } 15^{\circ} \mathrm{C} \text {. Low temperatures were not included. }\end{array}$ \\
\hline Geist et al. (2006) & Fall Chinook, Snake River, Idaho & $\begin{array}{l}\text { Constant and natural thermal regimes, saturated DO and less-than- } \\
\text { saturated DO }\end{array}$ \\
\hline EBMUD (1992) & Mokelumne River, California & $\begin{array}{l}\text { Fertilized hatchery eggs planted at } 20 \mathrm{~cm} \text { in incubation capsules in pipes. } \\
\text { Nineteen of } 29 \text { traps produced fry. Other factors besides temperature } \\
\text { were \%fines and flow. }\end{array}$ \\
\hline
\end{tabular}


These scaled, daily values were then combined across studies and used to develop unimodal relationships between survival and temperature. To combine data from studies, I calculated weighted average survival through life stage for each constant treatment temperature, using the initial number of eggs or alevins as a weight. In some cases, the initial number was a sum of eggs in multiple replicates. In other cases, the initial number of alevins was inferred to be the product of initial eggs and survival through the egg life stage.

An overview of unimodal functions typically used to fit biological temperature relationships is provided by Haefner (1997). Functions used in bioenergetics modeling typically represent a product of two functions (for example, logistic functions), one increasing and one decreasing. I selected the double Weibull model, which is very flexible and uses fewer parameters. Daily survival, $S$ was described by a double Weibull function with four parameters, two of which roughly represent lower (TL) and upper (TU) thresholds for high survival (Equation 10). Exponents, $k L$ and $k U$ control the steepness of descent for lower and upper temperatures, and should be odd numbers, where higher values are steeper. Converting to a daily survival requires that the value be raised to $1 /$ the duration of the life stage, $D$, as described in Equations 3 (eggs) and 4 (alevin). Let $L$ denote life stage (egg or alevin, Equation 10).

$$
S\left(T_{d}, L_{j, s, w}\right)=\left[\left(1-e^{-\frac{T}{T L} k L}\right) e^{-\frac{T}{T U} k U}\right]^{\frac{1}{D\left(T_{d}, L_{j, s, w}\right)}}
$$

Because data from several studies were combined, I weighted results for each treatment by the number of eggs initially used in the treatment. In some cases, the number was estimated from a reported range or a reported average. Parameter values were selected to minimize the weighted sum of absolute residuals between daily survival as predicted by a Weibull model and daily survival derived from experimental data. To fit Equation 10, I used a genetic algorithm ("genoud" package in R) to identify optimal values for four parameter (see R-program in Appendix A). The 'population size' used to explore parameter space was 500 individuals with a convergence tolerance of 1.0e-5. Constraints on the parameters selected were as follows: $1 \leq$ $T L \leq 14,1 \leq T U-T L \leq 20$ (in degrees C) $1 \leq 2 k L+1 \leq 15,1 \leq 2 k U+1 \leq 15$. $T L$ and the difference, $T U$ $T L$ were scaled by a factor of ten to allow more precision as this was solved as an integer problem.

\subsection{Literature review}

Most studies have evaluated survival of eggs and alevin reared at constant temperatures under laboratory conditions, but a few have evaluated natural temperature regimes. Many frequently referenced sources for temperature effects on early life stages are reports from those with extensive hatchery experience (e.g., Leitritz and Lewis, Fish Bulletin 107; Hinze et al. 1956), rather than replicated scientific studies. These sources were not included in the model fitting 
conducted here.

Several studies of fall Chinook eggs have reported lower limits of survival based on constant temperature treatments. Beacham and Murray (1989) determined that fall Chinook salmon eggs experienced complete mortality when incubated at $2^{\circ} \mathrm{C}$. Entiat and Skagit River Chinook salmon embryos reared at or below a constant temperature of $1.7^{\circ} \mathrm{C}$ did not survive to hatch (Combs and Burrows 1957). Eggs from the Nimbus Hatchery, Sacramento River drainage that were spawned and incubated at temperatures between 1.1 and $3.3^{\circ} \mathrm{C}$ suffered $100 \%$ mortality (Hinze 1959).

Low temperature extremes are better tolerated when they are encountered as part of a natural thermal regime (Groves et al. 2007). Combs and Burrows (1957) determined that Chinook eggs initially incubated at temperatures above $4.4^{\circ} \mathrm{C}$ were able to tolerate $1.7^{\circ} \mathrm{C}$ temperatures at later stages of incubation, but not when held at a constant $1.7^{\circ} \mathrm{C}$ temperature from the start. Seymour (1956) compared survival to hatch for eggs exposed to a constant $12.2^{\circ} \mathrm{C}$ temperature regime with survival under a simulated natural thermal regime (e.g., eggs deposited at $15.6^{\circ} \mathrm{C}$, reduced by $0.5^{\circ} \mathrm{C} \mathrm{d}^{-1}$ to $1.1^{\circ} \mathrm{C}$ for 5 days, maintained at $1.1^{\circ} \mathrm{C}$ for 20 days, and increased by $0.5^{\circ} \mathrm{C} \mathrm{d}^{-1}$ until hatch). Survival to hatch was higher when following the natural thermal regime (Seymour 1956). Geist et al. (2006) measured hatching and emergence success as a function of temperature and dissolved oxygen for fall Chinook salmon. Geist et al. focused on characterizing the upper end of the temperature range, showing a sharp decrease in survival between 16 and $16.7^{\circ} \mathrm{C}$ for natural regimes that started high and decreased by $0.2^{\circ} \mathrm{C} \mathrm{d}^{-1}$.

Other studies have focused on the upper end of the temperature range. Garling and Masterson (1985) compared survival for three constant-temperature treatments $\left(9.9,11.4,15.0^{\circ} \mathrm{C}\right)$. Survival to $50 \%$ hatch in the $15^{\circ} \mathrm{C}$ treatment was about half that in the two colder treatments where survival from hatch to emergence was about $75 \%$ of that in the two colder treatments. Unfertilized eggs were not distinguished from fertilized eggs, and thus survival may be underestimated (Garling and Masterson 1985). Beacham and Murray (1989) reported survival for fall Chinook eggs and for alevin reared at $17^{\circ} \mathrm{C}$ than for temperatures between 5 and $14^{\circ} \mathrm{C}$. Bjornn and Reiser (1991) reported a suitable thermal range for incubation between 5.0 and $14.4^{\circ} \mathrm{C}$. When compared with other studies, this range likely represents the range of highest survival. A similar threshold was reported by a field study in California. Experiments conducted by BioSystems in the Mokelumne River reported higher survival for eggs deposited in later redds that avoided exposure to temperatures above $15^{\circ} \mathrm{C}$ (EBMUD 1992). Egg to fry survival was 0.405 for the cold-water cohort and 0.095 for the warm-water cohort (EBMUD 1992). Eggs planted in two batches that represented the high-temperature cohort reached temperatures as high as 16.5 and $18^{\circ} \mathrm{C}$ early in development. 


\subsection{Model fitting results}

The model fitted suggests a broader tolerance for the alevin than for the egg lifestage (Figure 5). Parameter values for the double Weibull models for incubation survival were fitted using the approach described in Section 3.1 for both the egg and alevins lifestages. Solutions were obtained after only 1 and 3 generations for alevin and eggs, respectively. Results given in Table 4 include both the minimum-residual solution and a solution fitted "by eye". Note that the result for alevins is binding on the lower bound of $1^{\circ} \mathrm{C}$. This is consistent with the observation that older eggs and alevins tolerate low temperatures better than younger ones (Groves et al. 2007).

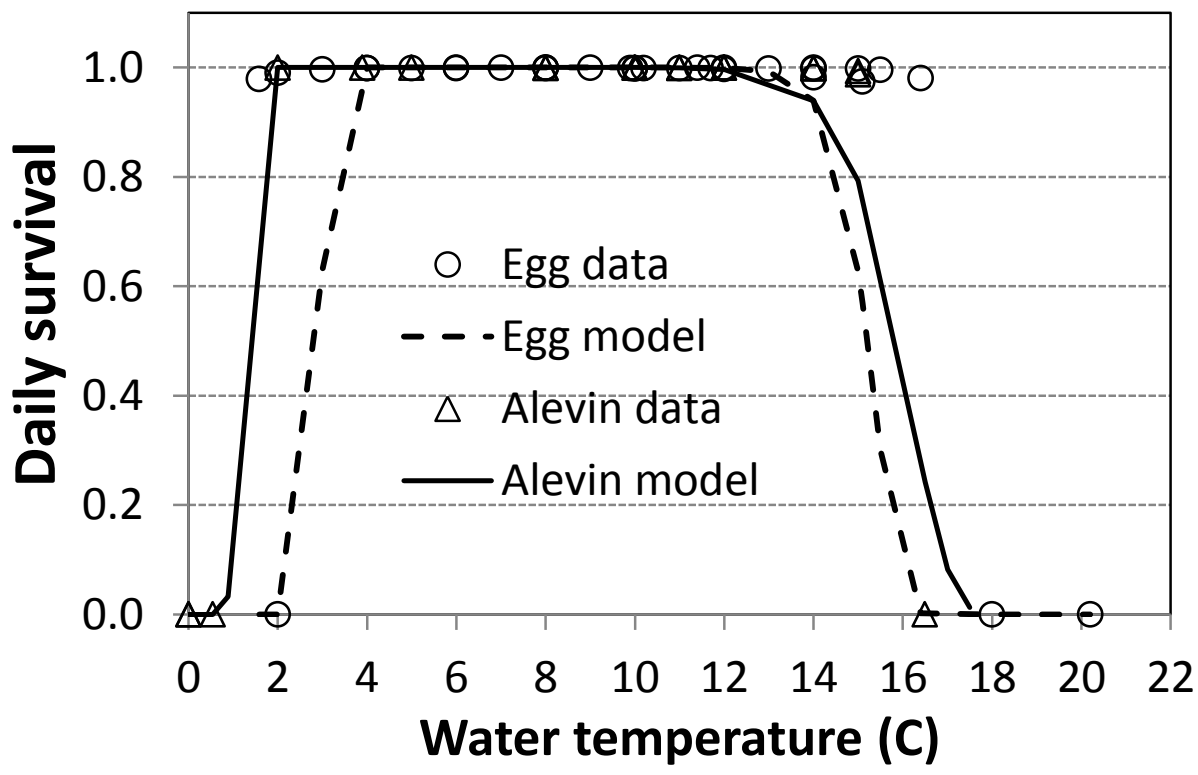

Figure 5. Modeled daily survival fitted to data from studies of fall Chinook salmon eggs and alevin compared with experimental data.

Table 4. Proposed values for parameters of double Weibull functions to describe survival. Exponents $\mathrm{kL}$ and $\mathrm{kU}$ must be odd integers.

\begin{tabular}{|l|r|r|r|r|}
\hline Parameter & \multicolumn{1}{l|l}{$\begin{array}{l}\text { Egg } \\
\text { (fitted) }\end{array}$} & $\begin{array}{l}\text { Egg } \\
\text { (by eye) }\end{array}$ & $\begin{array}{l}\text { Alevin } \\
\text { (fitted) }\end{array}$ & $\begin{array}{l}\text { Alevin } \\
\text { (by eye) }\end{array}$ \\
\hline TL & 3.0 & 3.5 & 1.0 & 1.5 \\
\hline TU & 15.4 & 16.5 & 16.2 & 16.0 \\
\hline kL & 25 & 5 & 27 & 25 \\
\hline kU & 29 & 25 & 19 & 25 \\
\hline Sum of residual absolute error & 0.0490 & & 0.0076 & \\
\hline
\end{tabular}




\subsection{Proposed simulation approach}

Two possible approaches can be used to implement temperature-related survival. The appropriate choice depends on whether other sources of mortality (e.g., superimposition) are represented. If not, an incubation sub-model can determine the number of surviving fry for each cohort and its emergence date (Figure 3 ). For each cohort $j, s$ the incubation sub-model tracks the product of daily temperature survival, $S$, described by Equation 8 with parameter values in Table 3 using parameters for the appropriate life stage for each week, $w$. At this time, there does not seem to be enough data to support modeling the effects of maternal (or paternal) exposure to elevated temperature, and an approach that represents delay of migration at elevated temperatures is supported.

Multiplying initial eggs in the cohort by $S$ (possibly drawing Poisson with mean $S$ ) gives the initial number of fry in the cohort at the time that it emerges, which becomes the initial count for the juvenile sub-model. Note that it is relatively simple to include a constant survival factor to represent mortality of eggs that are not fertilized and other sources of mortality that do not depend on the environment (Equation 11). This is important because otherwise the Bayesian fitting procedure will have to ascribe all incubation mortality to temperature.

$$
S_{j, s, w}=S_{c} \prod_{w=1}^{W} \prod_{d=7 w+1}^{7 w+7} S\left(T_{d}, L_{j, s, w}\right), L_{j, s, w}=\text { egg or alevin }
$$

\subsection{Discussion}

The models above are useful as tools for estimating temperature effects on survival for freshwater life stages of fall Chinook salmon. However, several assumptions should be kept in mind when using them and influence uncertainty in the results. First, predicting the timing or survival for early life stages from temperature assumes that water temperature in the channel is the same as that experienced in the gravel 1) that eggs and alevins are in the water. Dewatering of redds can expose eggs and alevin to wider temperature fluctuations, although alevin oxygen deprivation can be more important (McMichael et al. 2005). The influence of groundwater, both good (moderating temperature, removing metabolic wastes) and bad (anoxic water), is also important. In general, downwelling is thought to be most beneficial and upwelling tends to follow high flows. Site-to-site variation in gravel quality (\%fines) is also important, and alevin entrapment following superimposition is an important consideration (Carl Mesick Consultants 2002; Merz 2004; Jensen et al. 2009).

Timing of development, described by models in Section 2, can likely be assigned a relatively high degree of confidence, with the time required to migrate through gravel as one factor contributing to uncertainty. Colder temperatures can result in higher mortality simply because of the extended period of exposure at sub-optimal survival. 


\section{JUVENILE SURVIVAL}

\subsection{Methods}

More-recent studies of juvenile survival were reviewed, particularly those involving California stocks as well as studies of fall Chinook salmon in the Snake and Columbia Rivers. Two dynamic models and one survival model were reviewed. In addition, results reported by Sullivan et al. (2000) based on their review of juvenile Chinook salmon survival are presented. Sullivan et al. relied on experiments performed by Brett (1952), Blahm and McConnell (1970), and Coutant (1970).

\subsection{Literature review}

Several studies of smolts released in the Sacramento and San Joaquin rivers and captured downstream in the Bay-Delta indicate that temperature at release is one of the strongest predictors, with a negative effect on survival (Baker et al. 1995; Newman and Rice 2002). However, correlations among predictors were high. It should also be noted that early emigration, followed by rearing in the lower San Joaquin and estuary is a strategy successfully employed by San Joaquin fall Chinook salmon (Volker 2011).

The time of entry to seawater is a critical period. Juvenile fall Chinook salmon $1.5 \mathrm{~g}$ and larger are capable of tolerating seawater and growing after transfer, reaching optimal adaptability at 5 to $6 \mathrm{~g}$ (Clark and Shelbourne 1985). Larger juveniles are more likely to survive the parr-smolt transformation. Growth declines have been observed for juveniles entering seawater at temperatures exceeding $14.5^{\circ} \mathrm{C}$ (Clark and Shelbourne 1985). For this reason, the effects of temperature on growth are also relevant. The concern is that respiration costs increase with temperature. Nevertheless, most studies have found that salmonid growth is best at temperatures not far below upper limits when adequate prey is available. Three notable studies of juvenile fall Chinook survival have been conducted using hatchery juveniles from the San Joaquin-Sacramento basins, two lab studies and one field study. Hanson et al. (1997) studied the effects of constant and rising temperatures for Feather River stocks of fall Chinook salmon with 30 juveniles assigned to each temperature treatment. One feature of this study is that it included a control group. Dissolved oxygen was maintained at saturation, fish were acclimated to $18^{\circ} \mathrm{C}$. Results of the constant, instantaneous exposures showed that no juveniles lost equilibrium at $18^{\circ} \mathrm{C}$, all juveniles lost equilibrium within an hour when exposed to $27.0^{\circ} \mathrm{C}$, and mortality rates increased between $24.0^{\circ} \mathrm{C}$ and $25.0^{\circ} \mathrm{C}$. Feeding ceased at around $21.0^{\circ} \mathrm{C}$.

Cech and Myrick (1999) found growth to be highest at $19^{\circ} \mathrm{C}$ when prey was abundant, but this temperature resulted in negative growth under low prey conditions. They also determined the critical thermal maximum (CTM), which is calculated by quickly increasing temperatures in the laboratory. They found that ration did not have a significant effect on critical thermal 
maximum, which was around $28.8^{\circ} \mathrm{C}$ for juveniles acclimated to $19^{\circ} \mathrm{C}$. The authors concluded that Nimbus strain Chinook salmon performed well under temperatures up to $19^{\circ} \mathrm{C}$, provided that oxygen was available. Note that this CTM might be useful in conjunction with maximum daily temperatures, but that a lower threshold is appropriate for exposures over a longer time period, such as average daily temperatures. Field evidence for a CTM this high comes from a study of juvenile growth in floodplain by Jeffres et al. (2008). This study found that juveniles grew rapidly in a prey-rich floodplain environment with a daily average of $21^{\circ} \mathrm{C}$ and daily maximum of $25^{\circ} \mathrm{C}$. In contrast, Baker et al. (1995) reported an upper incipient lethal temperature of $23.01 \pm 1.08^{\circ} \mathrm{C}$ from a study of marked and released hatchery smolts recaptured in trawls in the Sacramento-San Joaquin River Delta. Thus, the temperature limit inferred from the Baker et al. field study was about $5^{\circ} \mathrm{C}$ lower than that determined under laboratory conditions or observed in the floodplain. Increased risk of predation is one possible explanation for this (see Coutant 1973) that might result from reduced growth, disorientation, or increased swim-speed of warm-water predators in the lower San Joaquin River. One would expect fewer predators to be present in a shallow floodplain.

Other studies have been performed in more-northern river systems. Recently, Geist et al. (2010) compared juvenile survival of Snake River fall Chinook salmon under steadily-rising temperatures, and under fluctuating thermal regimes. The critical thermal maximum under a steadily-rising thermal regime $\left(1.5^{\circ} \mathrm{C} \mathrm{h}^{-1}\right)$ was between 27.4 and $27.9^{\circ} \mathrm{C}$ (Geist et al. 2010). This rate of increase was chosen as one typical of those experienced by juveniles trapped in pools heated by solar radiation. A CTM was not calculated for the fluctuating regime, but $93.3 \%$ of mortalities occurred in systems that daily reached or exceeded $27^{\circ} \mathrm{C}$ (Geist et al. 2010). Sullivan et al. reviewed decreasing relationships between the temperature associated with $10 \%, 50 \%$, and $90 \%$ mortality (LC10, LC50, LC90) and increased duration of exposure for Chinook salmon. Experiments with juveniles and jacks acclimated to temperatures near $20^{\circ} \mathrm{C}$ subjected to elevated temperatures for $24 \mathrm{~h}$ were consistently associated with LC50's between 25 and $26^{\circ} \mathrm{C}$ (Coutant 1970, Brett 1952, Blahm \& McConnell 1970, reported in Sullivan et al. 2000), and an upper incipient lethal temperature of $24-25^{\circ} \mathrm{C}$ was reported by Brett (1952). The LC curves reported by Sullivan et al. (2000) were oddly close for 50 and $90 \%$ mortality, whereas the LC10 curve was lower as one would expect (Figure 6). The LC90 from this source seems suspect, as several other sources of information suggest a threshold LC90 close to $29^{\circ} \mathrm{C}$ (e.g., Geist et al. 2006, Hanson et al. 1997, Myrick \& Cech 2004).

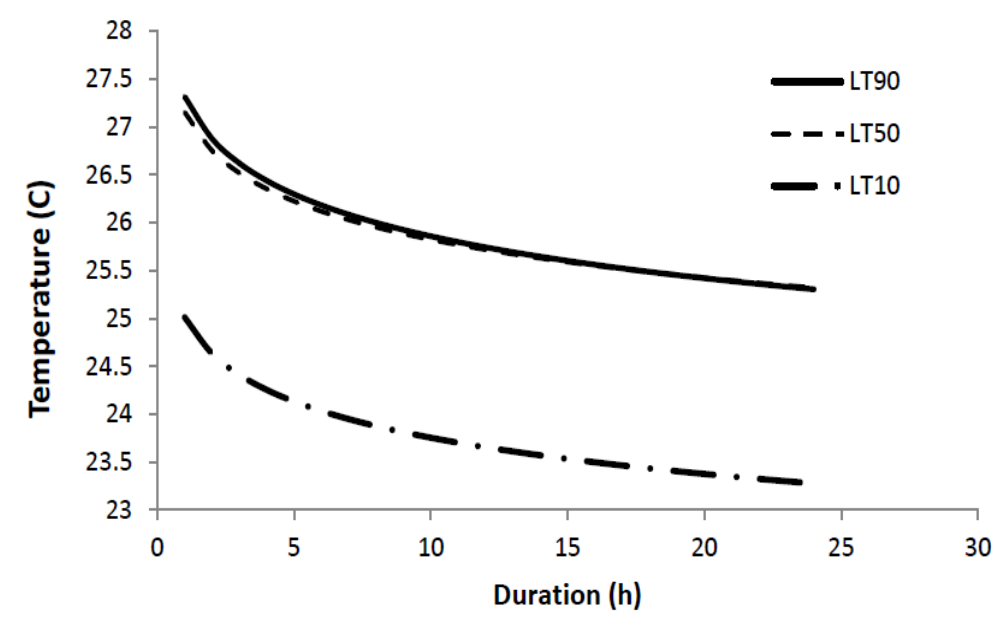

Figure 6. Duration-exposure curves for fall Chinook salmon fitted by Sullivan et al. (2000) to unpublished data collected by Blahm \& McConnell (1970). 
Spatial and temporal variability in temperature is likely an issue because of the widelyappreciated importance of acclimation (Sullivan et al. 2000). EAEST (1992, Appendix 20) reported that six fish were captured and moved to a live well in the Tuolumne River between 23.5 and $24.2^{\circ} \mathrm{C}$. Three originating from riffles with relatively lower temperatures of $20.4^{\circ} \mathrm{C}$ exhibited stress and were unable to hold position, and ultimately died, whereas those originating from riffles with higher temperatures recovered. Temperatures upstream below dams are relatively constant, whereas fish in middle parts of the rivers experience morevariable temperatures between low, constant release temperatures and diurnally fluctuating air temperatures.

Little is known about differences in temperature tolerance between fry and smolt life stages. Sauter et al. (2001) compared preferences of both spring and fall races during the smoltification process. Preferred temperature decreased for fall Chinook but not spring Chinook (Sauter et al. 2001), as indicated by a negative slope between temperatures selected and an index of smoltification (gill ATPase values). The highest values were $17.8^{\circ} \mathrm{C}$ and the lowest value was $11.1^{\circ} \mathrm{C}$. The authors suggest that use of cold-water refugia may help fall Chinook salmon to maintain high gill ATPase activity and seawater osmoregulatory function during emigration. Earlier studies have shown that smoltification, as measured by ATPase levels, are inhibited at elevated water temperatures (Zaugg 1981). Studies demonstrating desmoltification or linking the process to changes in survival have not, to my knowledge, been conducted.

\subsection{Review of simulation approaches}

\subsubsection{Empirical models based on field studies}

Field studies to release and recapture juveniles are the gold standard for quantifying survival. Typically, covariates, including temperature, are measured and used to develop site-specific empirical models. Baker et al. (1997) fitted the logistic survival model below based on temperature, $T_{r}$ at the time of release at Ryde and survival measured as the fraction of smolts captured in trawls at Chipps Island, $48 \mathrm{~km}$ downstream an average of 2 to 5 days later. Logistic survival models were fitted under a variety of distributional assumptions. Equation 12 shows one of the reported sets of estimated parameter values, $b_{1}=15.56$ and $b_{2}=-0.6765$.

$$
B(\operatorname{Tr})=\frac{1}{1+e^{-b_{1}-b_{2} T r}}
$$

Limitations of applying this model in San Joaquin tributaries are: 1) other sources of mortality 
unrelated to release temperature influenced survival that are not specifically accounted for in the model, 2) later temperatures experienced are unknown, but assumed to be correlated with release temperature, 3 ) dynamics of damage and repair caused by fluctuations in temperatures after release are not represented, and 4) the time period associated with the above survival is both short and uncertain (2-5 d), making it difficult to infer survival through shorter time intervals. The survival estimates were based on releases of smolt-sized hatchery fish transported to the release site from an unknown acclimation temperature. Upon release, smolt were exposed to elevated salinities and other water quality stressors that tend to reduce tolerance to high temperatures. Therefore, it is unclear how the model can be applied to presmolt juveniles in San Joaquin tributaries and upstream portions of the mainstem, or what an appropriate substitute for Trel would be in the Equation 12.

\subsubsection{Risk assessment models based on laboratory studies}

Risk assessment methodologies provide an alternative to logistic-type empirical models such as those fitted by Baker et al. and Newman and Rice (2003). These models are based on survival experiments conducted in the laboratory rather than field release-captures and their covariates. Sullivan et al. (2000) reviewed experiments for salmon and modeled relationships between temperature thresholds for survival as they decrease exponentially with increased duration of exposure (Figure 6).

Given a series of experimentally derived temperature thresholds corresponding with $p=10,50$, and $90 \%$ likelihood of survival, risk can be estimated for any time series of temperature exposures using the following rules. For example, if $\mathrm{p} \%$ of the population dies at each exposure based on the $L C(p)$, then the cumulative risk to the population is determined from the number of exceedances ( $n$ hours) experienced, Risk $=\left[1-(1-p)^{n}\right]$ and survival is $(1-p)^{n}$ (Sullivan et al. 2000). However, note that this relationship is not mathematically consistent with exponential duration models, and these will be compared below.

\subsubsection{Dynamic exposure models}

Modeling studies have begun to incorporate the idea of cumulative stress. Hines and Ambrose (unpublished data) constructed a temperature-duration curve for the Ten Mile Creek watershed in California. They developed logistic regressions to predict coho salmon presence because earlier work suggested that exceedance of four individual thresholds above $15^{\circ} \mathrm{C}$ were all found to be significant predictors and selecting one was not as predictive as including all thresholds, but the lowest (possibly because it included the others) explained the most variation. Although the idea of a temperature-duration curve is intriguing, it is misnamed because such a curve loses information about duration of exposure by taking temperature data out of its temporal context.

For this, a dynamic model is needed. The Stanislaus River Temperature Criteria Peer Review 
(1999) proposed a model based on cumulative degree days above an optimal temperature, $T_{\text {opt }}$, over a period of a week (Equation 13). An attempt was made to link these weighting values (here referred to as "Stress") with survival, as modeled by Baker et al. in order to calibrate the stress model.

$$
\operatorname{Stress}(t)=\left(T_{t}-T_{o p t}\right)^{\lambda}=\left(\frac{1-S_{T_{t}}}{1-S_{T_{o p t}}}\right)^{\lambda}
$$

Because it focuses on optimal temperature, this model is appropriate for fishes with narrow range of tolerance and it is unclear from Equation 13 how stress is defined for $T_{t}<T_{\text {opt. }}$

None of the models presented above provide for recovery when temperatures decrease. According to Sullivan et al. (2000), diel fluctuations in temperatures provide some protection from mortality. To cause direct mortality in natural stream environments, temperatures must exceed the highest short-duration temperatures (e.g., $26^{\circ} \mathrm{C}$ ). However, diurnal variation is lower in large rivers than in medium-sized ones (Caissie et al. 2006).

Bevelhimer and Bennett (2000) developed a dynamic model of cumulative thermal stress to evaluate the effects of chronic intermittent exposure to high temperatures using an hourly time step (Equation 14). Unlike the stress model in Equation 13, this model focuses on damage caused by exceeding the upper threshold. Threshold temperature above (below) which damage (recovery) occurs is $\theta$ and the ambient temperature is $T_{t}$. This model assumed that recovery occurred at a fraction $(\lambda=0.25)$ of the rate of stress accumulation.

$$
\text { Stress }_{t}=A_{t}-R_{t}, \text { where } \begin{cases}A_{t}=\sum_{k=0}^{t}\left(T_{k}-\theta\right) \text { and } R_{t}=0, & \left(T_{k}>\theta\right) \\ A_{t}=0 \text { and } R_{t}=\sum_{k=0}^{t} \lambda\left(\theta-T_{k}\right), & \left(T_{k} \leq \theta\right)\end{cases}
$$

This damage-repair model was developed to better understand the effects of load-following operations that can result in dramatic short-term fluctuations in temperatures below a dam, but has not yet been calibrated to predict survival for fall Chinook salmon. A damage-repair modeling approach would also be suitable for representing recovery and acclimation in response to natural diurnal fluctuations or use of thermal refuge provided by tributaries or areas influenced by groundwater.

However, one drawback of the damage-repair model in Equation 14 is that the model assumes that recovery is linearly related to the magnitude of deviation below the threshold, $\theta$. It seems more likely that a large, sudden decrease in temperature would have a detrimental effect and that a smaller one would be more beneficial. Thus, the model does not reflect our 
understanding that gradual changes are better tolerated than large, sudden changes in temperature. More work is needed to refine this approach and to outline a protocol for deriving its parameters.

\subsection{Proposed simulation approach}

\subsubsection{Logistic survival model with duration}

The proposed model is a logistic model describing survival of daily exposures to high water temperatures. This model can be defined by knowing any two points on the curve (Equation 15). Below, two points used are the threshold temperature at which $10 \%$ mortality occurs after $1 \mathrm{~h}$ of exposure (LC10) and the temperature at which $50 \%$ mortality occurs after $1 \mathrm{~h}$ exposure (LC50), based on Sullivan et al. (2000). To obtain survival through $n$-hours of exposure, there are two options, described by Equations 15 or 16 (these are compared in Table 6). Equation 15 assumes that survival through successive hours is independent and that these survivals can be multiplied to obtain survival through a longer period of length $n$-hours (Figure 7b). Equation 16 uses the duration relationships derived by Sullivan et al. to replace the LC threshold with one for the appropriate duration (Figure 7a).

$$
\begin{gathered}
S_{1, n}(T)=\left\{\frac{1}{1+e^{\left[\ln \left[\frac{(1-0.1)}{0.1}\right] \frac{T-L C 10(1)}{L C 90(1)-L C 10(1)}\right]}}\right\}^{n} \\
S_{2, n}(T)=\frac{1}{1+e^{\left[\ln \left[\frac{(1-0.1)}{0.1}\right] \frac{T-L C 10(n)}{L C 90(n)-L C 10(n)}\right]}}, \\
\operatorname{LT10}(n)=\frac{\log _{10}(60 \times n)-a}{b} ; a=21.6756 ; b=-0.7797, \\
\operatorname{LT} 50(n)=\frac{\log _{10}(60 \times n)-a}{b} ; a=20.5162 ; b=-0.7526 .
\end{gathered}
$$


a) Duration model

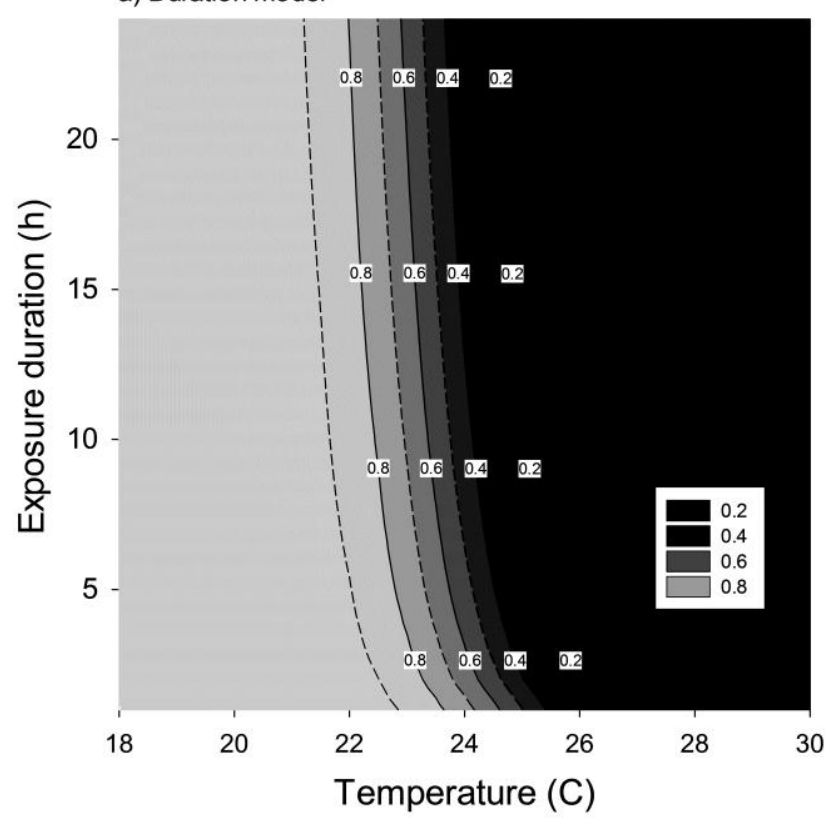

b) Multiplicative model

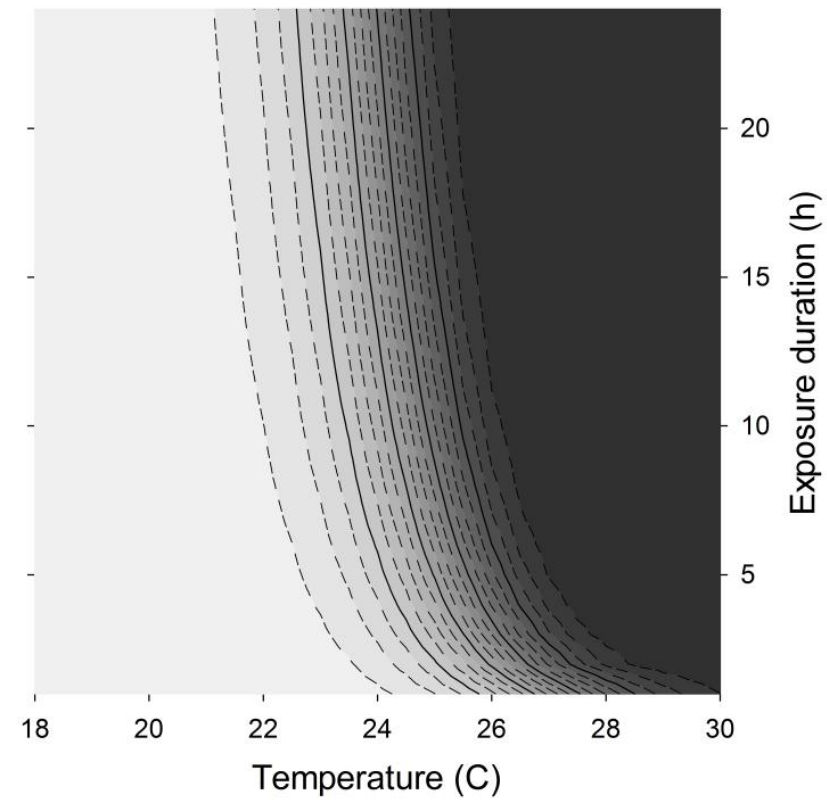

Figure 7. Logistic relationship between juvenile fall Chinook salmon survival and water temperature with duration effects estimated either a) using duration-specific thresholds or b) by assuming multiplicative survival as in $S_{1, n}$.

The multiplicative model is much easier to implement because it does not require breaking the time series into sequences exposed to the "same temperature," which may be tricky to define in practice. As noted earlier, the two approaches to representing duration effects behave similarly, but are not mathematically equivalent. The largest deviations are at intermediate (i.e., not extreme) high temperatures (Table 5). 
Table 5. Difference in two estimates of duration influence on logistic survival: Multiplicative hourly survival minus survival using duration-specific LC thresholds.

Duration (h)

\begin{tabular}{|c|c|c|c|c|c|c|c|c|c|c|c|c|c|c|c|c|c|c|c|c|c|c|c|c|}
\hline $\mathrm{T}(\mathrm{C})$ & 1 & 2 & 3 & 4 & 5 & 6 & 7 & 8 & 9 & 10 & 11 & 12 & 13 & 14 & 15 & 16 & 17 & 18 & 19 & 20 & 21 & 22 & 23 & 24 \\
\hline 18 & 0.001 & 0.001 & 0.001 & 0.001 & 0.001 & 0.001 & 0.001 & 0.001 & 0.001 & 0.001 & 0.001 & 0.001 & 0.001 & 0.001 & 0.001 & 0.001 & 0.001 & 0.001 & 0.001 & 0.001 & 0.001 & 0.001 & 0.001 & 0.001 \\
\hline 18.5 & 0.001 & 0.001 & 0.002 & 0.002 & 0.002 & 0.002 & 0.002 & 0.002 & 0.002 & 0.002 & 0.002 & 0.002 & 0.002 & 0.003 & 0.003 & 0.003 & 0.003 & 0.003 & 0.003 & 0.003 & 0.003 & 0.003 & 0.003 & 0.003 \\
\hline 19 & 0.002 & 0.002 & 0.003 & 0.003 & 0.003 & 0.004 & 0.004 & 0.004 & 0.004 & 0.004 & 0.004 & 0.004 & 0.004 & 0.004 & 0.004 & 0.004 & 0.004 & 0.004 & 0.004 & 0.004 & 0.004 & 0.004 & 0.004 & 0.004 \\
\hline 19.5 & 0.003 & 0.004 & 0.005 & 0.005 & 0.006 & 0.006 & 0.006 & 0.007 & 0.007 & 0.007 & 0.007 & 0.007 & 0.007 & 0.007 & 0.007 & 0.008 & 0.008 & 0.008 & 0.008 & 0.008 & 0.008 & 0.008 & 0.008 & 0.008 \\
\hline 20 & 0.005 & 0.007 & 0.008 & 0.009 & 0.010 & 0.010 & 0.011 & 0.011 & 0.012 & 0.012 & 0.012 & 0.012 & 0.012 & 0.013 & 0.013 & 0.013 & 0.013 & 0.013 & 0.013 & 0.013 & 0.013 & 0.013 & 0.013 & 0.013 \\
\hline 20.5 & 0.009 & 0.011 & 0.013 & 0.015 & 0.016 & 0.017 & 0.018 & 0.019 & 0.019 & 0.020 & 0.020 & 0.021 & 0.021 & 0.021 & 0.022 & 0.022 & 0.022 & 0.022 & 0.022 & 0.022 & 0.022 & 0.022 & 0.022 & 0.022 \\
\hline 21 & 0.014 & 0.019 & 0.022 & 0.025 & 0.027 & 0.029 & 0.030 & 0.031 & 0.032 & 0.033 & 0.034 & 0.035 & 0.035 & 0.036 & 0.036 & 0.036 & 0.037 & 0.037 & 0.037 & 0.037 & 0.037 & 0.037 & 0.037 & 0.037 \\
\hline 21.5 & 0.024 & 0.032 & 0.037 & 0.041 & 0.044 & 0.047 & 0.049 & 0.051 & 0.053 & 0.054 & 0.055 & 0.056 & 0.057 & 0.058 & 0.058 & 0.059 & 0.059 & 0.059 & 0.059 & 0.059 & 0.059 & 0.059 & 0.059 & 0.059 \\
\hline 22 & 0.039 & 0.051 & 0.060 & 0.066 & 0.071 & 0.075 & 0.079 & 0.081 & 0.084 & 0.085 & 0.087 & 0.088 & 0.089 & 0.090 & 0.090 & 0.090 & 0.091 & 0.091 & 0.090 & 0.090 & 0.090 & 0.089 & 0.089 & 0.088 \\
\hline 22.5 & 0.062 & 0.082 & 0.095 & 0.105 & 0.112 & 0.117 & 0.121 & 0.124 & 0.127 & 0.128 & 0.130 & 0.130 & 0.131 & 0.131 & 0.131 & 0.130 & 0.129 & 0.129 & 0.127 & 0.126 & 0.125 & 0.123 & 0.121 & 0.120 \\
\hline 23 & 0.099 & 0.128 & 0.146 & 0.158 & 0.166 & 0.172 & 0.175 & 0.178 & 0.179 & 0.179 & 0.179 & 0.178 & 0.176 & 0.174 & 0.172 & 0.169 & 0.166 & 0.163 & 0.160 & 0.156 & 0.152 & 0.148 & 0.144 & 0.140 \\
\hline 23.5 & 0.152 & 0.191 & 0.212 & 0.224 & 0.230 & 0.233 & 0.233 & 0.232 & 0.229 & 0.225 & 0.220 & 0.215 & 0.209 & 0.203 & 0.196 & 0.189 & 0.182 & 0.175 & 0.168 & 0.160 & 0.153 & 0.146 & 0.138 & 0.131 \\
\hline 24 & 0.224 & 0.268 & 0.285 & 0.291 & 0.290 & 0.285 & 0.277 & 0.267 & 0.256 & 0.244 & 0.232 & 0.220 & 0.207 & 0.195 & 0.182 & 0.170 & 0.158 & 0.146 & 0.134 & 0.123 & 0.112 & 0.101 & 0.091 & 0.081 \\
\hline 24.5 & 0.311 & 0.346 & 349 & 0.339 & 0.323 & 0.303 & 0.282 & 0.260 & 0.238 & 0.217 & 0.196 & 0.176 & 0.157 & 0.139 & 0.122 & 0.105 & 0.090 & 0.075 & 0.062 & 0.049 & 0.037 & 0.025 & 0.015 & 0.005 \\
\hline 25 & 0.399 & 0.406 & 0.380 & 0.345 & 0.307 & 0.269 & 0.234 & 0.201 & 0.170 & 0.142 & 0.116 & 0.093 & 0.072 & 0.053 & 0.036 & 0.021 & 0.008 & -0.005 & -0.015 & -0.025 & -0.034 & -0.041 & -0.048 & -0.054 \\
\hline 25.5 & 0.468 & 0.425 & .360 & 0.29 & 0.23 & 0.188 & 0.144 & 0.107 & 0.076 & 0.050 & 0.028 & 0.009 & -0.006 & -0.019 & -0.029 & -0.038 & -0.045 & -0.050 & -0.055 & -0.059 & -0.061 & -0.064 & -0.065 & -0.066 \\
\hline 26 & 0.499 & 0.391 & 0.288 & 0.204 & 0.139 & 0.089 & 0.051 & 0.022 & 0.000 & -0.016 & -0.027 & -0.036 & -0.042 & -0.046 & -0.049 & -0.051 & -0.052 & -0.052 & -0.052 & -0.052 & -0.051 & -0.051 & -0.050 & -0.049 \\
\hline 26.5 & 0.483 & 0.311 & 0.187 & 0.104 & 0.050 & 0.014 & -0.008 & -0.022 & -0.031 & -0.035 & -0.038 & -0.039 & -0.039 & -0.039 & -0.038 & -0.037 & -0.036 & -0.035 & -0.035 & -0.034 & -0.033 & -0.032 & -0.031 & -0.030 \\
\hline 27 & 0.424 & 0.211 & 0.093 & 0.031 & -0.001 & -0.018 & -0.025 & -0.028 & -0.029 & -0.029 & -0.028 & -0.027 & -0.026 & -0.025 & -0.024 & -0.023 & -0.022 & -0.021 & -0.021 & -0.020 & -0.019 & -0.019 & -0.018 & -0.018 \\
\hline 27.5 & 0.339 & 0.121 & 0.031 & -0.004 & -0.016 & -0.020 & -0.021 & -0.020 & -0.019 & -0.018 & -0.017 & -0.016 & -0.016 & -0.015 & -0.014 & -0.014 & -0.013 & -0.013 & -0.012 & -0.012 & -0.011 & -0.011 & -0.011 & -0.011 \\
\hline 28 & 0.251 & 0.058 & 0.003 & -0.012 & -0.015 & -0.014 & -0.013 & -0.013 & -0.012 & -0.011 & -0.010 & -0.010 & -0.009 & -0.009 & -0.008 & -0.008 & -0.008 & -0.007 & -0.007 & -0.007 & -0.007 & -0.007 & -0.006 & -0.006 \\
\hline 28.5 & 0.173 & 0.022 & -0.006 & -0.010 & -0.010 & -0.009 & -0.008 & -0.007 & -0.007 & -0.006 & -0.006 & -0.006 & -0.0 & -0.005 & -0.005 & -0.005 & -0.005 & -0.004 & -0.004 & -0.004 & -0.004 & -0.004 & -0.004 & -0.004 \\
\hline 29 & 0.114 & 0.006 & -0.006 & -0.007 & -0.006 & -0.005 & -0.005 & -0.004 & -0.004 & -0.004 & -0.004 & -0.003 & -0.003 & -0.003 & -0.003 & -0.003 & -0.003 & -0.003 & -0.002 & -0.002 & -0.002 & -0.002 & -0.002 & -0.002 \\
\hline 29.5 & 0.073 & 0.000 & -0.004 & -0.004 & -0.004 & -0.003 & -0.003 & -0.003 & -0.002 & -0.002 & -0.002 & -0.002 & 12 & -0.6 & -0 & -0.002 & -0.002 & -0.002 & -0.001 & -0.001 & -0.001 & -0.001 & -0.001 & -0.001 \\
\hline 30 & 0.045 & -0.001 & -0.003 & -0.002 & -0.002 & -0.002 & -0.002 & -0.002 & -0.001 & -0.001 & -0.001 & -0.001 & -0.001 & -0.001 & -0.001 & -0.001 & -0.001 & -0.001 & -0.001 & -0.001 & -0.001 & -0.001 & -0.001 & -0.001 \\
\hline
\end{tabular}




\subsubsection{Fitting to field data}

Ideally the model(s) above would be calibrated to in-river survival studies in the river of interest. Ideally a study would be planned that includes releases at a fairly wide range of temperatures. Different releases will be associated with different trajectories and associated environmental covariates. Survival estimates are scaled to the maximum across batches to minimize the effect of factors other than temperature. Juveniles must survive through $\mathrm{n}$ time intervals, where survival through each interval is a function of temperature exposure. Because temperature models have been calibrated to these rivers, for which historical climate, flow, and dam-release temperatures are known, one could reconstruct thermal histories associated with past survival studies.

An important aspect of the analysis would be to represent spatial heterogeneity in temperature. Ideally, tags would record thermal histories of individual fishes, but tags can potentially impact juvenile survival. Another alternative is to construct virtual trajectories of fish through a reconstructed thermal field. This could be simulated using an individual-based fish movement model. Given a random sample of reconstructed thermal trajectories, it would be possible to estimate parameters in Equation 15, as well as confidence limits.

\subsection{Discussion}

The challenge with modeling juvenile survival in the proposed San Joaquin model will be to estimate an integrated survival for weekly time steps represented in the model from survival estimates derived from experiments with much shorter, but lethal, exposure durations. When only long-term (i.e., weekly) statistical summaries of temperature are available, the focus on thermal maxima is appropriate because these are the temperatures most-likely to have an effect on survival. However, maximum and average temperatures are very highly correlated. Therefore, it makes little difference which is used as a predictor as long as the model's parameters are calibrated to field or laboratory survival data. This calibration step is important.

One concern is that a weekly temperature statistic might miss important spatial and temporal variation in the temperature regime encountered by fish. In some areas (e.g., shallow floodplains), heating may result in locally dangerous temperatures. In others areas, (e.g., groundwater influenced areas, tributaries), temperatures may be lower than in the mainstem. However, larger rivers tend to be well mixed and dominated by heat transfer between the airwater interface and tributary influences (Caissie 2005). One study, in the lower Snake River showed good correspondence between internally monitored [adult] body temperatures in salmon and average daily temperatures (Mann 2007). Finally, diurnal and flow-induced effects on exposure duration are lost when dealing with coarser-resolution data. Juveniles likely encounter a range of temperatures during the course of a week's time step.

Most models reviewed here were designed to integrate short-term fluctuations and operate on 
shorter time-scales (i.e., hourly), whereas the Baker et al. logistic model depends on release temperature, which is likely correlated with later temperatures encountered by smolts during migration. Although dynamic models were reviewed, those that represent stress and recovery have not reached the point of being calibrated to field or laboratory data. In future, research is needed to improve and test dynamic stress-recovery models.

\section{SUMMARY}

The motivation for this study was to recommend relationships for use in a model of San Joaquin fall Chinook salmon. This report reviews literature pertaining to relationships between water temperature and fall Chinook salmon. The report is organized into three sections that deal with temperature effects on development and timing of freshwater life stages, temperature effects on incubation survival for eggs and alevin, and temperature effects on juvenile survival. The following recommendations are made for modeling temperature influences for all three life stages.

1. Simulated upmigration by spawners should be inhibited until temperatures decrease to tolerable levels, i.e., $T_{d}<18.3^{\circ} \mathrm{C}$. Refined empirical spawning relationships that consider temperature effects, if consistent with this threshold, can be used to drive timing and locations of spawning in each river.

2. The duration of each life stage were described well by power and exponential functions of temperature for the two early life stages. This information is used to determine fractional development and to convert from survival through the life interval at constant temperatures to daily survival using temperatures that vary from day to day.

3. Alevin have a broader tolerance for extreme temperatures than do eggs. Daily survival is quite high for both life stages between $3^{\circ} \mathrm{C}$ and $14^{\circ} \mathrm{C}$. A double Weibull equation was fitted for each life stage for use in the incubation sub-model. In future, a modification to the Weibull model might be considered that allows the lower threshold, $T L$, and slope to vary with development degree days.

4. Total cohort survival from egg fertilization to emergence is the product of $S_{j, s, w}$ over all weeks prior to emergence. Note that this value is the same for all cohorts spawned in the same week, $w$ and river section, $s$. This can be used to estimate the number of surviving fry emerged by cohort.

In addition, gaps in knowledge are highlighted by the report. One problem that became evident in reviewing the literature on this subject was the tendency for statements about temperature effects to be repeated based on the same secondary sources, many of which were only weakly supported by scientific evidence (e.g., inadequately documented studies, unreplicated studies, studies of other salmonid species, or casual observations by hatchery operators). Many of these 
sources were reports that are difficult to locate. It would be useful if government agencies (and hatcheries) responsible for highly-cited reports to make these original sources available on-line. Secondly, this suggests a need for newer, better studies to document relationships between fall Chinook salmon and temperature. 


\section{REFERENCES}

Alderdice DF and FPJ Velsen (1978) Relation between temperature and incubation time for eggs of Chinook salmon (Oncorhynchus tshawytscha). Journal of the Fisheries Research Board of Canada 35:69-75

Baker PF, TP Speed and FK Ligon (1995) Estimating the influence of temperature on the survival of Chinook salmon smolts (Oncorhynchus tshawytscha) migrating through the Sacramento-San Joaquin river delta of California. Canadian Journal of Fisheries and Aquatic Sciences, 52:855-863

Beacham TD and CB Murray (1989) Variation in developmental biology of sockeye salmon (Oncorhynchus nerka) and Chinook salmon (O. tshawytscha) in British Columbia. Canadian Journal of Zoology 67:2081-2089

Beacham TD and CB Murray (1990) Temperature, egg size, and development of embryos and alevins of five species of Pacific salmon: a comparative analysis. Transactions of the American Fisheries Society 119:927-945

Berman CH (1990) The effect of elevated holding temperatures on adult spring Chinook salmon reproductive success. Master's thesis. University of Washington, Seattle, WA

Bevelhimer, MS and W Bennett (2000) Assessing cumulative thermal stress in fish during chronic intermittent exposure to high temperatures. Environmental Science and Policy 3: S211-S216

Blahm and McConnell (1970) Unpublished data cited in National Academy of Sciences and National Academy of Engineering (NAS/NAE). 1973

Brett JR (1952) Temperature tolerance in young Pacific salmon, Genus (Oncorhynchus). Journal of the Fisheries Research Board of Canada 9:265-323

Cassie D (2006) The thermal regime of rivers: a review. Freshwater Biology 51: 1389-1406.

Carl Mesick Consultants (2002) Initial Post-Project Evaluation Report. Knights Ferry Gravel Replenishment Project. Prepared for CALFED Bay Delta Program and Stockton East Water District. cmcfish@innercite.com

Clarke WC and JE Shelbourn (1985) Growth and development of seawater adaptability by juvenile fall Chinook salmon (Oncorhynchus tshawytscha) in relation to temperature. Aquaculture 45:21-31

Combs BD and Burrows R (1957) Threshold temperatures for the normal development of Chinook salmon eggs. Progressive Fish-Culturist 19:3-6

Connor WP, CE Piston and AP Garcia (2003) Temperature during incubation as one factor affecting the distribution of Snake River Fall Chinook salmon spawning areas. Transactions of the American Fisheries Society, 132:1236-1243

Coutant CC (1973) Effect of thermal shock on vulnerability of juvenile salmonids to predation. Journal of the Fisheries Research Board Canada 30:965-973

Crisp DT (1988) Prediction, from temperature, of eyeing, hatching and "swim-up" times for salmonid embryos. Freshwater Biology 19:41-48 
DWR (California Department of Water Resources) (1988) Water temperature effects on Chinook salmon (Oncorhynchus tshawytscha) with emphasis on the Sacramento River. A Literature Review. DWR Northern District

Garling D and M Masterson (1985) Survival of Lake Michigan chinook salmon eggs and fry incubated at three temperatures. The Progressive Fish Culturist 47: 63-66

Geist, DR, Abernethy, CS, Hand KD, Cullinan VI, Chandler, JA and PA Groves (2006) Survival, development, and growth of fall Chinook salmon embryos, alevins, and fry exposed to variable thermal and dissolved oxygen regimes. Transactions of the American Fisheries Society, 135:1462-1477

Goniea TM, ML Keefer, TC Bjornn, CA Peery, DH Bennett, and LC Stuehrenberg (2006) Behavioral thermoregulation and slowed migration by adult fall Chinook salmon in response to high Columbia River water temperatures. Transactions of the American Fisheries Society 135: 408-419

Groves PA and JA Chandler (2005) Habitat quality of historic Snake River fall Chinook salmon spawning locations and implications for incubation survival. Part 2: Intra-gravel water quality. River Research and Applications, 21:469-483

Groves PA, JA Chandler, and R Myers (2007) The Effects of the Hells Canyon Complex Relative to Water Temperature and Fall Chinook Salmon. Final Report submitted to the Federal Energy Regulatory Commission for Project Number 1971

Hallock RJ, RF Elwell, and DH Fry (1970) Migration of adult kind salmon Oncorhynchus tshawytscha in the San Joaquin Delta as demonstrated by the use of sonic tags. California Department of Fish and Game Bulletin 151. $92 \mathrm{p}$.

Hanson CR (1997) Acute temperature tolerance of juvenile Chinook salmon from the Mokelumne River. Final Report.Hanson Environmental, Inc., Walnut Creek, CA, 15 pp.

Heming TA and JE Mclnerney (1982) Effect of temperature and initial feeding in alevins of chinook salmon (Oncorhynchus tshawytscha). Canadian Journal of Fisheries and Aquatic Sciences, 39:1554-1562

Hinze JA (1959) Annual report Nimbus Salmon and Steelhead Hatchery fiscal year of 1957-1958. Calif. Dept. Fish. Game, Inland Fish. Admin. Rept. 59-4, 21 pp.

Jager HI, HE Cardwell, MJ Sale, MS Bevelhimer, CC Coutant and W VanWinkle (1997) Modelling the linkages between flow management and salmon recruitment in rivers. Ecological Modelling, 103:171-191

Jager HI, W Van Winkle, KB Lepla, JA Chandler, and P Bates (2002) Factors controlling white sturgeon recruitment in the Snake River. pp.127-150 IN: AFS Symposium: Biology, Management, and Protection of Sturgeon. American Fisheries Society, Bethesda, MD.

Jager HI and MJ Sale (2006) Functional Comparison between Predictions of a Chinook Salmon Model and Monitoring Data in the Tuolumne River, California. California Energy Commission. PIER Energy-Related Environmental Research. CEC-500-2006-098 
Jager HI (2011) Shaping Pulse Flows to Meet Environmental and Energy Objectives. Bi-annual report. ORNL/TM2010/228. Available on DOE-OSTI.

Jeffres CA, Opperman JJ, and PB Moyle (2008) Ephemeral Floodplain Habitats Provide Best Growth Conditions for Juvenile Chinook Salmon in a California River. Environmental Biology of Fishes 83: 449-458.

Jensen JOT and EP Groot (1991) The effect of moist air incubation conditions and temperature on Chinook salmon egg survival. American Fisheries Society Symposium, 10:529-538

Jensen JOT, WE McLean, T Sweeten, W Damon, and C Berg (2006) Puntledge River high temperature study: influence of high water temperatures on adult Chinook salmon (Oncorhynchus tshawytscha) in 2004 and 2005. Canadian Technical Report of Fisheries and Aquatic Sciences 2662. www.dfo-mpo.gc.ca/librariesbibliotheques/tech-eng.htm

Jensen DW, EA Steel, AH Fullerton, and GR Pess (2009) Impact of fine sediment on egg-fry survival of Pacific salmon: A meta-analysis of published studies. Reviews in Fisheries Science 17(3): 348-359.

Leitritz and Lewis. Trout and salmon culture: Hatchery methods. Reprinted as California Fish Bulletin 164. University of California Publication 4100. Accessed May 26, 2010 at http://books.google.com/books?id=4w93EbtEFMYC\&printsec=frontcover\#v=onepage \&q\&f=false

Mann RD (2007) The effects of high temperature exposures on migration success and embryo quality of Snake River adult Chinook salmon and steelhead, MS Thesis, University of Idaho

Marine KR and JJ Cech, Jr. (2004) Effects of high water temperature on the growth, smoltification, and predator avoidance in juvenile Sacramento River Chinook Salmon. North American Journal of Fisheries Management 24: 198-210

McMichael GA, Rakowski CL, James BB, Lukas JA (2005) Estimated fall Chinook salmon survival to emergence in dewatered redds in a shallow side channel of the Columbia River. North American Journal of Fisheries Management 25: 876-884

McMichael, GA, JA Vucelick, BJ Bellgraph, TJ Carlson, RL McComas, L Gilbreath, SG Smith, B Sandford, G Matthews, and JW Ferguson (2007) A study to estimate salmonid survival through the Columbia River estuary using acoustic tags, 2005 and 2006 Synthesis Report. Technical Memo PNNL-SA-54927. 16 pp. Available on DOE's OSTI

Mebane W, jr and J Sekhon. R Genoud package documentation and vignettes. On-line: http://sekhon.berkeley.edu/rgenoud/, last accessed 9/10/2011

Merz J, JD Setka, GB Pasternack, and JM Wheaton (2004) Predicting benefits of spawning-habitat rehabilitation to salmonid (Oncorhynchus spp.) fry production in a regulated California river. Canadian Journal of Fisheries and Aquatic Sciences 61: 1433-1446

Murray CB and JD McPhail (1988) Effect of incubation temperature on the development of five species of Pacific salmon (Oncorhynchus) embryos and alevins. Canadian Journal of Zoology 66:266-273 
Myrick, C (1999) Steelhead and Chinook Salmon Bioenergetics: Temperature, Ration, and Genetic Effects, University of California, Davis, California.

Myrick CA and JJ Cech, Jr (2004) Temperature effects on juvenile anadromous salmonids in California's Central Valley: what don't we know? Reviews in Fish Biology and Fisheries, 14:113-123

Newman KB and J Rice (2002) Modeling the survival of Chinook salmon migrating through the lower Sacramento River. Canadian Journal of Fisheries and Aquatic Sciences 97(460): 983-993.

Richter A and SA Kolmes (2005) Maximum temperature limits for Chinook, coho, and chum salmon, and steelhead trout in the Pacific Northwest. Reviews in Fisheries Science 13:23-49

Sams RE and KR Conover (1969) Water quality and the migration of fall salmon in the Lower Willamette River, Final Report. Fish Commision of Oregon. Portland, OR

Sauter ST, LI Crawshaw, and AG Maule (2001) Behavioral thermoregulation by juvenile spring and fall Chinook salmon, Oncorhynchus tshawytscha, during smoltification. Environmental Biology of Fishes 61: 296-304.

Seymour AH (1959) Effects of temperature upon the formation of vertebrae and fin rays in young Chinook salmon. Transactions of the American Fisheries Society 88:58-69

Shrimpton JM, Zydlewski JD and JW Heath (2007) Effect of daily oscillation in temperature and increased suspended sediment on growth and smolting in juvenile chinook salmon, Oncorhynchus tshawytscha. pp. 269-276

STCPR (Stanislaus Temperature Criteria Peer Review) (2004) Peer Review of Water Temperature Objectives Used as Evaluation Criteria for the Stanislaus - Lower San Joaquin River Water Temperature Modeling and Analysis. Deas M, J Bartholow, C Hanson, and C Myrick. AD Consultants. 54 pp.

Strange, JS (2010) Upper thermal limits to migration in adult Chinook salmon: Evidence from the Klamath River Basin. Transactions of the American Fisheries Society 139: 1091-1108.

Sullivan K, DJ Martin, RD Cardwell, JE Toll, and S Duke (2000) An analysis of the effects of temperature on salmonids of the Pacific Northwest with implications for selecting temperature criteria. Sustainable Ecosystems Institute, Portland Oregon. sei@sei.org.

Volk EC, Bottom DL, Jones KK, Simenstad CA (2011) Reconstructing Juvenile Chinook Salmon Life History in the Salmon River Estuary, Oregon, Using Otolith Microchemistry and Microstructure. Transactions of the American Fisheries Society 139: 535-549.

Yates D, H Galbraith, D Purkey, A Huber-Lee, J Seiber, J West, S Herrod-Julius, and B Joyce (2008) Climate warming, water storage, and Chinook salmon in California's Sacramento Valley. Climate Change DOI 10.1007/s10584-008-9427-8.

Zaugg WS (1981) Advanced photoperiod and water temperature effects on gill Na+-K+ adenosine triphosphatase activity and migration of juvenile steelhead (Salmo gairdneri). Canadian Journal Fisheries and Aquatic Sciences 38: 758-764. 


\section{APPENDIX A. R-code to fit survival models as a function of incubation temperature.}

\#\#

\#\# Fit Weibull models for temperature-related incubation survival

\#\# for fall Chinook salmon based on laboratory studies with constant temperature

\#\# Read data

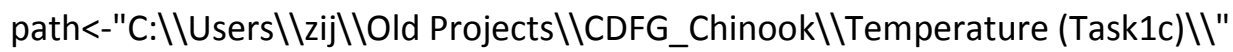

filename<-paste(path,"TempMortality.csv",sep="'")

InData $<-$ read.table(filename, skip $=0$, header $=$ TRUE, colClasses $=$

c(rep("numeric",7),"character","numeric"), sep = ",", quote="\"'", dec=".", fill = TRUE)

InData <- as.data.frame(InData[, 1:9])

\# Starting parameter values are in th0

\# (1) Tlo, (2) Tdel, (3) kL, (4) kU values on [1-11]

th0 $<-c(3.5,9.0,2,12)$

low $<-c(1,1,1,1)$

up $<-c(14,20,15,15)$

scale $<-c(10,10,1,1)$

up $<-$ up * scale

low $<-$ low $*$ scale

\#Data <- data.frame(subset(InData, Lifestage==0, select=c(WTdegC, Daily.survival, Neggs)))

Data <- data.frame(subset(InData, Lifestage $==1$, select=c(WTdegC, Daily.survival, Neggs)))

names(Data) <- c("WT","Sdata","Neggs")

library("rgenoud")

outpath <- paste(path, "genout", sep="")

$M<-\operatorname{genoud}(\mathrm{fn}=$ Res, Sdata=Data\$Sdata, $\mathrm{WT}=$ Data $\$ \mathrm{WT}$, scale=scale, wgts=Neggs, nvars=4, $\max =\mathrm{FALSE}$, data.type.int $=T R U E$, starting.values $=N U L L$, pop.size $=500$, max.generations $=50$, wait.generations $=3$, hard.generation.limit=TRUE, Domains=cbind(low, up), solution.tolerance $=0.00001$,

MemoryMatrix $=$ FALSE, print $=3$, int.seed $=13191$,

project.path=outpath, output.append=TRUE, share.type=FALSE, boundary.enforcement=2)

th1 <- M\$par/ scale

\#\# Plot results

library("ggplot2")

WT <- seq $(0,30,0.5)$

S $<-$ Surv_incub(th1, WT)

theme_set(theme_bw())

$\mathrm{P}$ <- ggplot ()$+$ geom_line $(\operatorname{size}=1$, aes $(\mathrm{x}=\mathrm{WT}, \mathrm{y}=\mathrm{S}))+\mathrm{xlab}($ "Water temperature C") + ylab("Incubation survival")

$P<-P+$ opts(axis.title. $x=$ theme_text(size $=12$, vjust $=0.5)$, axis.title. $y=$ theme_text(size $=12$, angle $=90$, vjust $=0.5)$ )

\#\# Daily survival function of temperature 
\#\# Returns a vector of daily survival values

Surv_incub <- function(th0, WT)

\{

STlo $<-$ th0[1]

SThi $<-$ th0[1] + th0[2]

\# Force steepness parameters, pkL, pkU to be odd integer

$\mathrm{STKL}<-$ th0[1]

STKL $<-$ floor $(2 * S T k L)+1$

STkU $<-$ th0[2]

STkU $<-$ floor $(2 *$ STkU $)+1$

\# Calculate Weibull survival function for temperature vector WT

$\mathrm{S}<-\left(1-\exp \left(-(\mathrm{WT} / \mathrm{ST} / \mathrm{lo})^{\wedge} \mathrm{STkL}\right)\right)^{*} \exp \left(-(\mathrm{WT} / \mathrm{SThi})^{\wedge} \mathrm{STkU}\right)$

\}

return $(S)$

\# Residuals = actual - predicted by Weibull model

Res <- function(theta, Sdata, WT, scale, wgts)

\{

$\mathrm{S}=$ na.omit(Sdata)

\# Unscale parameters

theta <- theta / scale

\# Calculate estimated survival from temperature

Sest <- Surv_incub(theta, WT)

Res $<-$ S - Sest

WRes <- wgts * Res

return (sum(abs(WRes))/sum(wgts))

\} 
APPENDIX B. Temperature survival data for incubation

\begin{tabular}{|c|c|c|c|c|c|c|c|c|}
\hline WTdegC & Survival & ScaledSurvival & Neggs & DaysToHatch & $\begin{array}{l}\text { Daily } \\
\text { survival }\end{array}$ & Lifestage & Source & $\begin{array}{l}\text { ImputedDa } \\
\text { ys }\end{array}$ \\
\hline 2 & 0.14 & 0.1489 & 231 & 202 & 0.9906 & 0 & M\&M1988 & 0 \\
\hline 5 & 0.83 & 0.883 & 240 & 101.5 & 0.9988 & 0 & M\&M1988 & 0 \\
\hline 8 & 0.94 & 1 & 243 & 67.1 & 1 & 0 & M\&M1988 & 0 \\
\hline 11 & 0.9 & 0.9574 & 248 & 46.9 & 0.9991 & 0 & M\&M1988 & 0 \\
\hline 14 & 0.48 & 0.5106 & 229 & 38.4 & 0.9826 & 0 & M\&M1988 & 0 \\
\hline 1.583 & 0.0057 & 0.0057 & 800 & 248.1 & 0.9794 & 0 & C\&B1957 & 1 \\
\hline 3 & 0.5825 & 0.586 & 800 & 162.9 & 0.9967 & 0 & C\&B1957 & 1 \\
\hline 4 & 0.895 & 0.9004 & 800 & 129 & 0.9992 & 0 & C\&B1957 & 1 \\
\hline 6 & 0.9687 & 0.9745 & 800 & 89 & 0.9997 & 0 & C\&B1957 & 1 \\
\hline 7 & 0.992 & 0.998 & 800 & 76.3 & 1 & 0 & C\&B1957 & 1 \\
\hline 9 & 0.994 & 1 & 800 & 58.7 & 1 & 0 & C\&B1957 & 1 \\
\hline 10 & 0.959 & 0.9648 & 800 & 52.4 & 0.9993 & 0 & C\&B1957 & 1 \\
\hline 13 & 0.943 & 0.9487 & 800 & 39.1 & 0.9987 & 0 & C\&B1957 & 1 \\
\hline 14 & 0.939 & 0.9447 & 800 & 35.9 & 0.9984 & 0 & C\&B1957 & 1 \\
\hline 15.5 & 0.876 & 0.8813 & 800 & 31.9 & 0.996 & 0 & C\&B1957 & 1 \\
\hline 9.9 & 0.489 & 0.9722 & 400 & 50 & 0.9994 & 0 & G\&M1985 & 0 \\
\hline 11.4 & 0.503 & 1 & 400 & 43 & 1 & 0 & G\&M1985 & 0 \\
\hline 15.1 & 0.231 & 0.4592 & 400 & 30 & 0.9744 & 0 & G\&M1985 & 0 \\
\hline 2 & 0 & 0 & 4136 & NA & 0 & 0 & B\&M1989 & 0 \\
\hline 4 & 0.8783 & 0.8836 & 4393 & 128.9 & 0.999 & 0 & B\&M1989 & 0 \\
\hline 8 & 0.994 & 1 & 4079 & 69.9 & 1 & 0 & B\&M1989 & 0 \\
\hline 12 & 0.988 & 0.994 & 4004 & 43.5 & 0.9999 & 0 & B\&M1989 & 0 \\
\hline 15 & 0.9337 & 0.9393 & 4075 & 34.8 & 0.9982 & 0 & B\&M1989 & 0 \\
\hline 10.2 & 0.75 & 0.9603 & 32 & 51.2 & 0.9992 & 0 & J\&G1991 & 0 \\
\hline 11.7 & 0.759 & 0.9718 & 29 & 43.6 & 0.9993 & 0 & J\&G1991 & 0 \\
\hline 14 & 0.781 & 1 & 32 & 35.8 & 1 & 0 & J\&G1991 & 0 \\
\hline 16.4 & 0.424 & 0.5429 & 33 & 31.5 & 0.9808 & 0 & J\&G1991 & 0 \\
\hline 18 & 0 & 0 & 33 & 32 & 0 & 0 & J\&G1991 & 0 \\
\hline 20.2 & 0 & 0 & 30 & 17.8 & 0 & 0 & J\&G1991 & 0 \\
\hline 6 & 0.929 & 0.9346 & 120 & 95 & 0.9993 & 0 & H1982 & 0 \\
\hline 8 & 0.917 & 0.9225 & 120 & 71 & 0.9989 & 0 & H1982 & 0 \\
\hline 10 & 0.907 & 0.9125 & 120 & 55 & 0.9983 & 0 & H1982 & 0 \\
\hline 12 & 0.893 & 0.8984 & 120 & 44 & 0.9976 & 0 & H1982 & 0 \\
\hline 2 & 1 & 1 & 32 & 114 & 1 & 1 & M\&M1988 & 0 \\
\hline 5 & 1 & 1 & 192 & 89.5 & 1 & 1 & M\&M1988 & 0 \\
\hline
\end{tabular}




\begin{tabular}{|l|l|l|l|l|l|l|l|l|}
\hline 8 & 0.95 & 0.95 & 217 & 47.9 & 0.9989 & 1 & M\&M1988 & 0 \\
\hline 11 & 0.96 & 0.96 & 208 & 37.1 & 0.9989 & 1 & M\&M1988 & 0 \\
\hline 14 & 0.97 & 0.97 & 111 & 24.6 & 0.9988 & 1 & M\&M1988 & 0 \\
\hline 10 & 0.98 & 0.99391 & 196 & 42.6 & 0.9999 & 1 & G\&M1985 & 1 \\
\hline 11 & 0.986 & 1 & 201 & 37.8 & 1 & 1 & G\&M1985 & 1 \\
\hline 15 & 0.737 & 0.74746 & 92 & 23.5 & 0.9877 & 1 & G\&M1985 & 1 \\
\hline 3.9 & 0.99 & 0.99298 & 4049 & 85.4 & 0.9999 & 1 & B\&M1989 & 0 \\
\hline 8 & 0.997 & 1 & 4050 & 49.5 & 1 & 1 & B\&M1989 & 0 \\
\hline 12 & 0.989 & 0.99198 & 3956 & 33.6 & 0.9998 & 1 & B\&M1989 & 0 \\
\hline 15 & 0.83167 & 0.83417 & 3830 & 27.3 & 0.9934 & 1 & B\&M1989 & 0 \\
\hline 10 & 1 & 1 & 24 & 42.6 & 1 & 1 & J\&G1991 & 1 \\
\hline 12 & 1 & 1 & 22 & 33.6 & 1 & 1 & J\&G1991 & 1 \\
\hline 14 & 0.96 & 0.96 & 25 & 26.5 & 0.9985 & 1 & J\&G1991 & 1 \\
\hline 16.5 & 0 & 0 & 14 & 19.7 & 0 & 1 & J\&G1991 & 1 \\
\hline
\end{tabular}

